DR ANEES BAHJI (Orcid ID : 0000-0002-3490-314X)

Article type : Systematic Review or Meta-analysis

\title{
Reduction in Mortality Risk with Opioid Agonist Therapy: A Systematic Review and Meta-Analysis
}

Anees Bahji ${ }^{1,2}$, Breagh Cheng ${ }^{1}$, Samantha Gray ${ }^{1}$, Heather Stuart ${ }^{1}$

1. Department of Public Health Sciences, Queen's University, Kingston, Ontario, Canada

2. Department of Psychiatry, Queen's University, Kingston, Ontario, Canada

Correspondence: Anees Bahji, MD

ORCID: https://orcid.org/0000-0002-3490-314X

PGY5, Department of Psychiatry, Queen's University

PhD Candidate, Department of Public Health Sciences, Queen's University

Abramsky Hall, Room 328, 21 Arch Street, Kingston, ON, Canada K7L 3N6

Tel: 613 533-6000 Ext. 33355

Fax: 613 533-6388

Email: 0ab104@queensu.ca

\section{Article Metrics}

- Abstract Manuscript Figures: 9

- Tables: 3

- Appendices: 11

- References: 76

- Keywords: humans; buprenorphine; methadone; opioid-related disorders; drug overdose; analgesics, opioid; systematic review; meta-analysis

\section{Declarations}

- On behalf of all authors, the corresponding author declares there are no relevant conflicts of interest

\section{Funding}

- There is no funding to report for this project.

This article has been accepted for publication and undergone full peer review but has not been through the copyediting, typesetting, pagination and proofreading process, which may lead to differences between this version and the Version of Record. Please cite this article as doi: 10.1111/acps.13088

This article is protected by copyright. All rights reserved. 


\section{Acknowledgements}

- The authors would like to thank Dylan Ermacora for his support with statistical analysis, and the research librarians at the Bracken Health Sciences Library at Queen's University.

\section{Data Sharing Statement}

- Data used in this analysis will be provided freely through the Open Science Framework upon completion of the study.

\section{ABSTRACT \\ Introduction}

Opioid agonist therapies are effective medications that can greatly improve the quality of life of individuals with opioid use disorder. However, there is significant uncertainty about the risks of cause-specific mortality in- and out-of-treatment.

\section{Objective}

This systematic review and meta-analysis explored the association between methadone or buprenorphine with cause-specific mortality among opioid-dependent persons.

\section{Methods}

We searched six online databases to identify relevant cohort studies, calculating all-cause and overdose-specific mortality rates during periods in- and out-of-treatment. We pooled mortality estimates using multivariate random effects meta-analysis of the crude mortality rate per 1000 person-years of follow-up as well as relative risks comparing mortality inversus-out of treatment.

\section{Results}

32 cohort studies (representing 150,235 participants, 805,423.6 person-years, and 9112 deaths met eligibility criteria. Crude mortality rates were substantially higher among methadone cohorts than buprenorphine cohorts. Relative risk reduction was substantially higher with methadone relative to buprenorphine when time in-treatment was compared to time out-of-treatment. Furthermore, the greatest mortality reduction was conferred during the first four weeks of treatment. Mortality estimates were substantially heterogeneous, and varied significantly by country, region, and by the nature of the treatment provider.

\section{Conclusion}

Precautions are necessary for the safer implementation of opioid agonist therapy, including baseline assessments of opioid tolerance, ongoing monitoring during the induction period, education of patients about the risk of overdose, and coordination within healthcare services.

This article is protected by copyright. All rights reserved. 


\section{INTRODUCTION}

Opioid use disorder (OUD) is a substantial contributor to the global burden of disease and mortality (1). In 2010, there were 15.5 million opioid dependent persons globally, accounting for 9.2 disability adjusted life years (DALYs) - a $73 \%$ increase from 1990 (1). In addition to premature mortality and disability, OUD not only has a profound impact on the quality of life of affected individuals, but also their families and society as a whole (1). In recent years, the opioid overdose crisis has become a major global public health concern, which shows no signs of slowing down (2).

Given growing concerns about opioid dependence and opioid overdose mortality, there has been increasing demand for effective, evidence-based treatments for OUD and for the prevention of opioid overdose mortality (2-4). Many countries have responded to the opioid crisis by increasing the availability of the rapid-acting opioid antagonist naloxone, which can quickly reverse the effects of an opioid overdose (5). National and international medical bodies are also collaborating to develop opioid prescribing standards and guidelines with the intent of improving opioid stewardship $(6,7)$. The success of these efforts, however, are dependent on the identification of at-risk patients and improved access to harm reduction interventions (2).

A disproportionate amount of opioid overdose fatalities occur among individuals who are opioid dependent. Therefore, finding effective treatments for OUD is expected to be a major component of the solution to the opioid overdose epidemic. Opioid agonist therapies (OATs) are a safe and effective class of medications that can greatly improve the quality of life of opioid dependent persons $(2,3)$. OATs, including methadone and buprenorphine, suppress opioid cravings and withdrawal (3), reduce illicit opioid use (8), decrease criminality $(9,10)$, and lower the risk of drug-related HIV transmission (11-13). These therapies are particularly effective when they are combined with one or more evidence-based psychosocial interventions, such as motivational interviewing (14) or contingency management (15).

There is a wealth of evidence supporting the use of the long-acting synthetic opioid agonist methadone for the treatment of opioid withdrawal and the management of opioid dependence. Methadone is the best-researched and first widely-used opioid agonist for the treatment of opioid dependence (12). The partial opioid receptor agonist buprenorphine has become increasingly popular in the last decade for its superior safety profile while retaining efficacy for the dual treatment of opioid withdrawal and dependence $(13,16)$. Opioid agonist therapies are also effective for the management of opioid dependence in pregnancy, and can reduce the risk of neonatal abstinence syndrome (17).

Growing evidence, however, suggests that mortality during and after OAT is timedependent and agent-specific $(3,18-20)$. For example, methadone is associated with higher rates of mortality during the induction phase of OAT if initial doses are too high, owing to its full-agonist properties at the $\mu$-opioid receptor (21). Conversely, the partial agonist buprenorphine self-titrates activity at the $\mu$-opioid receptor, causing a ceiling effect (13). Due to this effect, methadone is superior at retaining patients in OAT treatment relative to buprenorphine (13). This has been cited as a major limitation in buprenorphine therapy because mortality risk is thought to increase abruptly after discontinuation of OAT $(19,20)$.

Despite the global prevalence of opioid use, there have been few studies looking specifically at the burden of opioid overdose mortality in general, let alone among those with opioid use disorder. Effect estimates from available individual studies have not been conclusive due to limited statistical power from small sample sizes, number of events, and low exposure prevalence. As individual cohort studies have been underpowered to detect nuances in mortality risks, and randomized controlled trials are unlikely to be feasible for this purpose. An alternative approach is necessary.

This article is protected by copyright. All rights reserved. 
A systematic review and meta-analysis would allow for the appraisal of available evidence regarding opioid overdose mortality rates, provide a more precise estimate of the exposure effect of opioid agonist therapy on mortality, and help explain heterogeneity in the findings of individual studies. As a synthesis of research findings, a meta-analysis would provide a summary of effect measures, as well as determine necessity and questions for future research. Systematic reviews and meta-analyses are particularly valuable in distilling the differential risks of mortality associated with different times and types of opioid agonist therapy by pooling together the results of several cohort studies.

While Sordo and colleagues carried out a meta-analysis on this topic in 2017 (18), it was limited by having only three studies of buprenorphine, and only half of the papers (10 in total) explored overdose specific mortality. The study was only able to identify a total of three buprenorphine cohorts, severely limiting their ability to make grounded conclusions about its impact on overdose mortality. Furthermore, the majority of articles captured by their meta-analysis focused on all-cause mortality, with only half (ten of nineteen cohorts) exploring opioid overdose specific mortality. This is particularly relevant in the wake of the current global opioid epidemic. As several additional studies have been published on this topic since 2017, we considered that an updated synthesis was warranted.

Therefore, our objective was to estimate the association between exposure to opioid agonist therapy and all-cause and overdose-specific mortality among individuals with opioid use disorder.

\section{METHODS \\ Registration}

This review was registered with the Open Science Framework on June 14, 2019 (https://osf.io/nhs7y/). Although an a priori protocol was used, it was not published online in advance of the review.

\section{Data Sources}

We searched seven online databases (Medline, Embase, PsycINFO, CINAHL, Cochrane CENTRAL Library, Allied and Complementary Medicine, ProQuest, and Web of Science) by using different combinations of free text and data-base specific index terms related to the topics of opioid dependence, opioid agonist treatment, mortality, and cohort studies. Details of the full search strategy are provided in Appendix 1. The search was conducted in January 2019 and updated in June 2019. As a complement to this search, we also reviewed the reference lists of relevant original papers and reviews. We followed both the PRISMA and MOOSE guidelines (Appendix 2) for reporting systematic reviews and meta-analyses throughout $(22,23)$.

\section{Eligibility criteria}

We included cohort studies comparing mortality among people with opioid dependence. To be eligible, studies had to include follow-up data during and after opioid agonist treatment with methadone or buprenorphine. The following eligibility criteria were applied:

1. Study designs

a. Included: cohort studies

b. Excluded: clinical trials, case-control studies, cross sectional surveys, case reports, case series, qualitative research, editorials, methods, reviews, research letters, protocols

This article is protected by copyright. All rights reserved. 
2. Population

a. Included: adults with opioid dependence

b. Excluded: non-human studies (e.g., preclinical studies, animal studies)

3. Exposure

a. Included: any opioid agonist therapy (including methadone or buprenorphine maintenance)

b. Excluded: studies with unknown treatment

4. Outcome

a. Included: studies providing aggregate or raw data on all-cause and overdosespecific causes of death over a defined follow-up period (e.g., number of deaths and person years broken down by follow-up period in and out of treatment)

b. Excluded: studies where insufficient data was provided to enable computation of mortality rates during periods in and out of treatment

5. Other

a. For cohorts spanning several reports, we used data from the primary cohort and excluded overlapping follow-up periods from each report.

\section{Study selection and data extraction}

Two reviewers independently completed all aspects of the systematic review process (screening records by title and abstract, reviewing full-text articles, data extraction, and quality assessment rating) using Cochrane's Covidence, a systematic review manager. Disagreements were resolved by consensus with an additional reviewer.

For each eligible study, we retrieved information on baseline population characteristics, including study location, sex and age distribution, primary opioid of misuse, and prevalence of opioid injection, non-opioid drug use, HIV infection, and psychiatric and medical comorbidity; number of cohort participants entering opioid agonist treatment during the study period (untreated participants and those under other types of treatment were excluded); treatment features, including drug type (methadone or buprenorphine), average daily dose, induction method (inpatient or ambulatory), and provider (addiction medicine specialist or general practitioner); and main follow-up characteristics, including calendar period, average length of follow-up from the start of maintenance treatment (excluding any previous detoxification period), loss to follow-up, and mortality outcomes.

We also registered detailed information on the number of deaths, person years at risk, and mortality rates from all causes and overdose during follow-up periods in and out of treatment and, whenever possible, during specific time intervals since treatment initiation and cessation.

\section{Quality assessment}

We used a 9-item quality assessment framework for non-randomized observational studies, which we adapted from a previous meta-analysis exploring opioid-related mortality in order to capture ratings for times in-and-out of opioid agonist therapy (20). This included a general appraisal of case ascertainment, measurement, diagnosis, statistical measures, completeness, representativeness, and age/sex estimates. Total quality scores ranged from 0 to 19 , with higher scores indicating higher study quality. Details of the quality assessment tool and a perstudy rating of quality are described in Appendix 3.

This article is protected by copyright. All rights reserved. 


\section{Publication bias assessment}

Publication bias was assessed qualitatively — by examining funnel plots for gross symmetryand quantitatively, using the Egger and trim-and-fill methods (24-26). These are described further in Appendices 4 and 5.

\section{Statistical analysis}

For each selected cohort, we calculated crude all-cause and overdose-specific mortality rates during periods in and out of treatment by dividing the number of deaths registered in each period by the person years contributed. This approach allowed us to estimate pooled mortality rates pooled rate differences and rate ratios comparing periods in and out of treatment. Therefore, the specific effect sizes used in this meta-analysis were rate ratios for mortality during periods in versus out of treatment.

When not explicitly reported, we obtained the number of person years by treatment period from the available summary statistics. All-cause and overdose-specific mortality rates in and out of treatment were jointly combined across all methadone or buprenorphine cohorts by using a bivariate random effects meta-analysis on log transformed mortality rates in both treatment periods $(27,28)$.

For treatment cohorts that reported mortality data by time interval in and out of treatment, we combined cause-specific mortality rates before and after four weeks of treatment using a multivariate random effects meta-analysis with log-transformed mortality rates during these treatment intervals.

To evaluate whether mortality rates differed by baseline population characteristics, treatment delivery, and follow-up features of treatment cohorts, we extracted the following moderator variables:

- Publication year

- Proportion HIV+ (\%)

- Proportion with psychiatric comorbidity (\%)

- Proportion male (\%)

- Average dose of buprenorphine or methadone (mg)

- Nature of opioid agonist therapy provider (general practitioner, specialist, mixed)

- Proportion who injected opioids (\%)

- Country of study

- Quality score

- Mean age (years)

Due to insufficient reporting of all variables, we performed bivariate meta-regression analysis to assess the combined impact of each moderator variables separately on the mortality risk reduction associated with opioid agonist therapy. We fit all models using restricted maximum likelihood methods with unstructured between-cohort covariance matrices in the $\mathrm{R}$ package metafoR (29). We also conducted subgroup analyses to stratify cohorts by type of opioid agonist (e.g., buprenorphine vs. methadone).

\section{Assessment and management of heterogeneity}

We examined the overall heterogeneity across studies visually by way of Forest plots, but also quantitatively by examining the Cochran $\chi^{2}$ test and the $I^{2}$ statistic, which described the proportion of total variation in study specific mortality rates because of heterogeneity.

Consistent with previous literature $(18,30,31)$, we categorized $I^{2}$ values using $<25 \%, 25-50 \%$, and $>50 \%$ as representative of low, moderate, and high heterogeneity, respectively. We

This article is protected by copyright. All rights reserved. 
anticipated a very high level of statistical heterogeneity between studies. After reviewing the Cochrane guidelines (32), we applied the following seven strategies to address heterogeneity.

1. First, we confirmed that the data were correctly extracted and entered into our statistical program.

2. Second, we considered the possibility of not doing a meta-analysis but opted against this as we wanted to measure the intervention effect of opioid agonist therapy.

3. Third, given the large number of studies identified, we explored causes of heterogeneity by conducting subgroup analyses investigating characteristics of studies that were pre-specified in our review protocol.

4. Fourth, we conducted sensitivity analyses by conducting a fixed-effects metaanalyses, which ignores heterogeneity; the pooled effect estimate from a fixed-effect meta-analysis is normally interpreted as being the best estimate of the intervention effect.

5. Fifth, we performed a random-effects meta-analysis, which may be used to incorporate heterogeneity among studies. Although this is not a substitute for a thorough investigation of heterogeneity, it can be helpful to quantify heterogeneity that cannot be explained.

6. Sixth, we assessed the impact of using an alternative effect measure, as heterogeneity may be an artificial consequence of an inappropriate choice of effect measure. For example, the choice of effect measure for dichotomous outcomes (odds ratio, relative risk, or risk difference) may affect the degree of heterogeneity among results.

7. Seventh, we explored the impact of excluding studies, as some heterogeneity may be due to the presence of one or more outlying studies with results that conflict with the rest of the studies. Although it is generally unwise to exclude studies from a metaanalysis on the basis of their results as this may introduce bias, it is advisable to perform analyses both with and without outlying studies as part of a sensitivity analysis. The influence of each study on pooled estimates was evaluated via sensitivity analysis with leave-out-one meta-analysis, allowing the removal of each individual study from the analysis.

\section{RESULTS}

\section{Systematic review findings}

Of the 2506 distinct records identified by our search strategy, we selected 32 distinct cohorts from 28 articles $(33-50,50-55,19,56-59)$ for inclusion in the meta-analysis (Figure 1).

\section{Study characteristics}

Tables 1 and 2 show the main characteristics of selected cohorts. The studies were published between 1974 and 2018 and were all carried out in high income countries: eighteen in Europe, five in North America, five in Australia, and two in Asia. There were mixed baseline prevalences of opioid injection and HIV infection, except six cohorts $(38,39,42,53,54,56)$ that enrolled only opioid injectors, two of them further restricted to patients positive for HIV $(39,57)$. There was limited information on psychiatric and medical comorbidities. More than $70 \%$ of participants were men, and the mean age at baseline ranged from 23.4 to 39.6 (Table 1).

All 32 studies reported all-cause mortality during follow-up periods in and out of treatment, of which 21 also reported opioid overdose-specific mortality. Methadone was prescribed in 27 cohorts including 129,248 participants over the period 1965-2015. Buprenorphine was prescribed in five cohorts including 20,987 participants over 1990-2010 (Table 2). Average daily doses of methadone ranged from $47 \mathrm{mg}$ to $116 \mathrm{mg}$, while average doses of buprenorphine ranged from $10 \mathrm{mg}$ to $12 \mathrm{mg}$. Treatment was initiated on an 
ambulatory basis in 14 cohorts, primarily recent ones, and provided by addiction medicine specialists in 13 cohorts and general practitioners or mixed staff in ten cohorts. The average duration of follow-up varied from 0.5 to 13.9 years for methadone and 1.0 to 4.5 years for buprenorphine.

Overall all-cause and overdose-specific mortality rates among opioid agonist therapy users The all-cause mortality rates varied widely $\left(I^{2}=98.62 \%, p<0.001\right.$, Figure 2$)$. The overall allcause crude mortality rate (CMR) was 16 deaths per 1000 person-years (PY) of follow-up (95\% confidence interval $[\mathrm{CI}], 14-17$ deaths per $1000 \mathrm{PY}$ ). Mortality rates were substantially higher among methadone users $(\mathrm{CMR}=17$ deaths per $1000 \mathrm{PY}, 95 \% \mathrm{CI}, 15-20)$ than buprenorphine users (CMR $=7$ deaths per $1000 \mathrm{PY}, 95 \% \mathrm{CI}, 6-8)$.

Similarly, the overdose-specific varied widely $\left(I^{2}=97.52 \%, \mathrm{p}<0.001\right.$, Figure 3$)$. The overall overdose-specific CMR was 6 overdose deaths per $1000 \mathrm{PY}$ of follow-up (95\% CI, 57 deaths per $1000 \mathrm{PY})$. Again, mortality rates were substantially higher among methadone users (CMR $=6$ overdose deaths per $1000 \mathrm{PY}, 95 \% \mathrm{CI}, 5-7)$ than buprenorphine users (CMR $=3$ overdose deaths per $1000 \mathrm{PY}, 95 \% \mathrm{CI}, 3-4)$.

\section{Overall all-cause and overdose-specific mortality rate reduction among opioid agonist therapy users in-versus-out-of-treatment}

The overall all-cause mortality rate was significantly lower during periods in opioid agonist therapy treatment compared to periods out of treatment (risk ratio $(\mathrm{RR})=0.372,95 \% \mathrm{CI}$, $0.322-0.430$, Figure 4$)$. The mortality risk reduction was significantly greater with methadone $(\mathrm{RR}=0.350,95 \% \mathrm{CI}, 0.300-0.408)$, however, the overall mortality reduction was not statistically significant among buprenorphine users $(\mathrm{RR}=0.630,95 \% \mathrm{CI}, 0.364-1.092)$

Similarly, the overdose-specific mortality rate reductions were 0.266 overall $(95 \% \mathrm{CI}$, 0.204-0.348, Figure 5) 0.258 with methadone (95\% CI, 0.194-0.342), and 0.556 with buprenorphine $(95 \%$ CI, 0.083, 3.74). Again, the buprenorphine sample did not lead to a statistically significant reduction in overdose-specific mortality rates.

\section{All-cause and overdose-specific mortality rate reduction in-vs-out of treatment during the first four weeks and after four weeks of treatment with opioid agonist therapy}

The relative risk of mortality during the first four weeks of opioid agonist treatment was 0.279 (95\% CI, 0.130-0.599, Figure 6) for those in treatment compared to those not in treatment. Similarly, the relative risks were $0.304(0.123-0.753)$ and $0.234(0.120-0.458)$ for methadone and buprenorphine, respectively.

Similarly, the relative risk of overdose mortality during the first four weeks of treatment was $0.445(0.372-0.531$, Figure 7$)$ for those in treatment compare to those who were not. The relative risks were $0.429(0.350-0.526)$ and $0.546(0.325-0.919)$ for methadone and buprenorphine, respectively.

After four weeks of treatment, the relative risk of all-cause mortality with opioid agonist therapy was not statistically significantly for those in versus out of treatment $(\mathrm{RR}=$ $0.412,95 \%$ CI, 0.128-1.328, $I^{2}=82.06 \%$, Figure 8). However, the relative risk of overdosespecific mortality with opioid agonist treatment was significantly lower $(\mathrm{RR}=0.455,95 \%$ CI, 0.315-0.656, $I^{2}=73.03 \%$, Figure 9).

\section{Analysis of potential moderating variables}

We conducted bivariate meta-regression analysis to separately explore the impact of all prespecified variables on all-cause and overdose-specific mortality rate reductions in-versus-outof-treatment with opioid agonist therapy —-these are outlined in Table 3.

This article is protected by copyright. All rights reserved. 
For all-cause mortality rate reduction, the type of opioid agonist therapy, prescriber, and geographic region were significant moderators: mortality rate reduction was greater with methadone (relative to buprenorphine), with addiction specialist providers (relative to others), and in North America and Asia (relative to Europe and Australia).

For overdose-specific mortality rate reduction, the proportion who injected opioids and publication year of the study were also significant moderators, with greater mortality rate reduction as the proportion of injection drug use and publication year increased. Similar to all-cause mortality, region and type of provider were statistically significant; however, the type of opioid agonist therapy was not statistically associated with overdose mortality risk.

Assessment of publication bias for all-cause and overdose-specific mortality rates are provided in Appendices 4 and 5, respectively. Using both qualitative (funnel plot) and quantitative methods (Egger's test, Trim \& Fill), we found little evidence suggestive of publication bias. For overdose-specific mortality, trim-and-fill suggested there was one missing study; however, augmentation with this one study did not significantly impact our mortality estimates $(p=0.5588)$.

\section{Sensitivity analyses}

We explored the influence of each study on pooled estimates via sensitivity analysis with leave-out-one meta-analysis, allowing the removal of each individual study from the analysis (Appendices 6 and 7 for all-cause and overdose-specific mortality rate reduction estimates).

\section{Additional analyses of crude all-cause and overdose-specific mortality rates}

We conducted additional analyses to further explore the absolute and relative differences in all-cause mortality rates (Appendices 8 and 9, respectively) and overdose-specific mortality rates (Appendices 10 and 11, respectively).

\section{DISCUSSION}

In our review, we identified 32 cohort studies, summing 150,235 participants, 805,423.6 person-years, and 9112 deaths, including 3801 overdoses. Our findings suggest that enrollment in opioid agonist therapy with methadone and buprenorphine reduces all-cause and overdose-specific mortality - particularly during the first four weeks of treatment.

Although methadone and buprenorphine showed similar trends in mortality over time, buprenorphine was associated with lower all-cause and overdose-specific mortality rates than methadone, which is consistent with its established superior safety profile. We tended to observe larger relative effect sizes, as measured by the rate ratio, for overdose than all-cause deaths with methadone but not buprenorphine, which is also consistent with previous literature emphasizing differential safety profiles of the two opioid agonist therapies. Our findings that the first four weeks after the onset and cessation of methadone treatment are the highest risk periods suggest these are key periods during which to focus efforts for prevention of drug-related deaths. These findings are important because some patients cycle in and out of OAT and are therefore exposed to repeated periods of high risk for mortality (20). Such changes primarily reflect changes in the risk of fatal overdose - and this has been more accurately assessed in the present meta-analysis as we were able to identify a larger number of cohorts specifically reporting overdose deaths.

The increased mortality risk during the first few weeks of treatment could be explained by the bioaccumulation of methadone, which often exceeds opioid tolerance in the early stages of treatments (60). Psychological factors and concomitant use of other respiratory depressant drugs or cocaine could also synergistically increase mortality risk (18). We also observed large increases in mortality in the first four weeks after cessation compared, which could be explained by the loss of tolerance to opioids - assuming that many patients may resume illicit opioid use (18). This parallels the observed trends in drug-related

This article is protected by copyright. All rights reserved. 
mortality in other scenarios where opioid tolerance is probably diminished, for example, after prison release (53) or hospital discharge (60). Lifestyle factors and comorbid conditions may also increase all-cause mortality, as deaths from suicide and injury are also more common during this high-risk period (61).

Data from five cohorts (three from Australia) suggest that opioid agonist therapy with buprenorphine can reduce all-cause mortality. However, the disparity in mortality rates in periods in and out of treatment did not reached statistical significance for either all-cause or overdose-specific mortality. Other sources of data have suggested that buprenorphine could be more effective than methadone in reducing mortality, especially from overdose $(45,62,63)$. Unlike methadone, there is a ceiling for respiratory depressant effects of buprenorphine as dose increases, and the probability of triggering arrhythmias is lower (64-66).

When we compared mortality between periods in and out of treatment, we found a greater reduction in mortality with methadone than with buprenorphine (measured as the rate difference or rate ratio between periods). When we compared mortality between them-first within the treatment period and then in the period off treatment — we found a significantly lower mortality with buprenorphine than methadone in both periods.

This meta-analysis synthesized all available evidence from 32 cohort studies published until 2018 on the risk of mortality in people who are dependent on opioids during and after opioid agonist treatment, separately for buprenorphine and methadone. We have updated previous time-dependent mortality patterns reported for both methadone and buprenorphine with the most recently available data (18).

\section{Heterogeneity}

Despite the strengths of this study, the high level of statistical heterogeneity represents a key limitation to the interpretation of its findings. The existence of heterogeneity suggests that there may not be a single intervention effect but rather, a distribution of intervention effects. This suggests that the receipt of opioid agonist therapy on its own does not necessarily impact mortality risk, but rather, the combination of opioid agonist therapy and other variables may account for the observed findings .

While random-effects meta-analysis is the most commonly used meta-analysis model when heterogeneity is encountered (28), authors often compare estimates obtained from random-effects modelling to those from a fixed-effect model - which in contrast, assumes there is no heterogeneity between studies (67-71). However, the use of fixed-effects models is controversial as such estimates may not be realistic, particularly when studying real-world phenomenon that are highly heterogenous. In any case, we compared fixed- and randomeffects estimates as a form of sensitivity analysis. For example, for the comparison of allcause mortality comparing in-versus-out-of-treatment periods, the relative risk for mortality was 0.37 (95\% CI, 0.32-0.43, $\left.I^{2}=84 \%\right)$ using random-effects modeling, and 0.41 (95\% CI, $0.39-0.43, I^{2}=84 \%$ ) with a fixed-effects model. These differences indicate that there is substantial residual heterogeneity in our sample that cannot be fully explained using measured covariates.

In consultation with the Cochrane guidelines (72), we followed additional strategies to address heterogeneity. We confirmed that the data were correctly extracted and entered into our statistical program by reviewing and resolving discrepancies between reviewers. Although meta-analyses are often abandoned in the face of substantial between-study heterogeneity, we opted to pursue meta-analysis alongside a rigorous attempt to explain the observed heterogeneity. We explored causes of heterogeneity by conducting subgroup analyses investigating characteristics of studies that were pre-specified in our review 
protocol, such as the type of opioid agonist, in-versus-out of treatment, and the duration of treatment (up to 4 weeks and after 4 weeks): each of these reduced the total heterogeneity slightly, but not substantially.

Ultimately, we presented random-effects meta-analysis to incorporate heterogeneity among studies. We also assessed the impact of using an alternative effect measure - such as the odds ratio and risk difference - but this did not lead to substantial changes in heterogeneity.

\section{Limitations}

Several additional limitations of this study must also be taken into consideration. First, as the same patients enrolled in treatment are followed over time, they may enter and re-enter treatment at multiple timepoints - often in a non-random way-hence creating potential for confounding in the comparisons of all-cause and overdose-specific mortality risks in and out of treatment.

Second, although some studies provided diverse demographic and clinical data on the baseline characteristics of study participants, adjustment for these potential confounders often produced similar or even increased out-to-in mortality rate ratios, merely reflecting that the above conditions tended to be less prevalent at baseline among patients who later left or were discharged from treatment than those who remained in treatment. As these baseline characteristics were not measured at each point of contact, we are unable to obtain unbiased estimates of the preventive effect of OAT on all-cause and overdose-specific mortality. Individual cohort studies are prone to confounding and selection bias because of differential loss to follow-up, however, this is difficult to assess without the available information on the magnitude and direction of bias projected onto the pooled mortality estimates.

Third, as there were almost no studies representative of low- and middle-income countries, this limits the generalizability of our mortality estimates to these countries.

Fourth, as follow up was often spread over many decades, with highly variable average lengths of follow-up. The bulk of our data reflect mortality among males. As some studies suggest overdose and all-cause mortality experiences among opioid users is different between males and females, this is a significant limitation of our study.

Fifth, as very few studies reported sex-specific mortality figures, we were not able to conduct sex-stratified sub-analyses to address this potentially interesting analysis. This would have been valuable and is a potential area for future research to focus on more in-depth.

Sixth, delayed records of treatment cessation may have led to the misclassification of out-of-treatment deaths as occurring in-treatment, which would make our estimates on the impact of OAT on mortality more conservative. Similarly, misclassification between overdose and non-overdose death due to inconsistent definitions and coding of causes of death would tend towards underestimating deaths due to overdose.

Seventh, our study is limited to studies using controlled opioid agonist therapies. As such, we have not captured mortality estimates from OAT initiated in the illicit drug market.

Eight, differences in mortality might also reflect confounding through differences in characteristics of patients, such as age, severity of opioid dependence, injection drug use, other drug use, comorbidities, prison history, overdose history, patient's preference); characteristics of treatment (such as previous treatment, specialization of the doctor who controls the treatment, dose, provision characteristics, cointerventions, retention, or drop outs), or the sociopolitical context in which studies have been conducted. For example, the initial prognosis might be better in those given buprenorphine than those given methadone (that is, fewer comorbidities, milder opioid dependence) $(19,49,50,73)$, although this was not clearly found in a recent US study (74). The role of such confounding factors has received almost no empirical examination. As very few details on patient or treatment characteristics

This article is protected by copyright. All rights reserved. 
were reported in the component articles in this meta-analysis (Tables 1 and 2), this precluded a more detailed examination of this potential issue and the possibility of an assessment for confounding. A previous sensitivity simulation analysis, however, has suggested that the comparatively lower mortality associated with buprenorphine related to methadone in the first four weeks of treatment was unlikely to be due to unmeasured confounding (19).

Ninth, the quality assessment framework used was an adaptation of a previously used 11-item instrument; as such, it has not been specifically validated for the purposes addressed in this review and may not be optimal for use in meta-analysis. Tenth, despite multiple attempts to explain and account for heterogeneity — such as with subgroup analyses - there remained substantial residual heterogeneity in our meta-analysis estimates; as a result, it may be invalid to pool the results and generate a single summary estimate.

\section{Significance of Findings}

Globally, the number and proportion of deaths attributable to opioid use is substantial. Overdoses remain preventable causes of death, which warrant wider implementation of harmreduction and preventive interventions. Our review provides evidence that OAT reduces mortality among opioid-dependent persons, but in order to establish causality, further research utilizing study designs that can assess for a wide range of confounding variables are needed. Future studies, such as multicentered cohort studies directly comparing opioid agonists in a head-to-head manner, would be helpful in determining the comparative effectiveness of methadone and buprenorphine for morality reduction, controlling for relevant confounders. Further studies should be conducted in low-and middle- income countries to address gaps in knowledge.

\section{Conclusions}

Although methadone and buprenorphine are listed as essential medicines, coverage remains low in many countries worldwide (75). Collaboration between policy makers, clinicians and researchers is needed to improve access to these treatments. Our findings suggest that precautions are necessary for the safer implementation of opioid agonist therapy, including baseline assessments of opioid tolerance, ongoing monitoring during the induction period, education of patients about the risk of overdose during treatment, and coordination of patients within healthcare services. Efforts to improve retention in treatment remain important as a strategy to reduce mortality. Although our review identified a lower risk of mortality associated with buprenorphine, making wide-sweeping generalizations about the relative offering of treatments is beyond the scope of this review.

This article is protected by copyright. All rights reserved. 


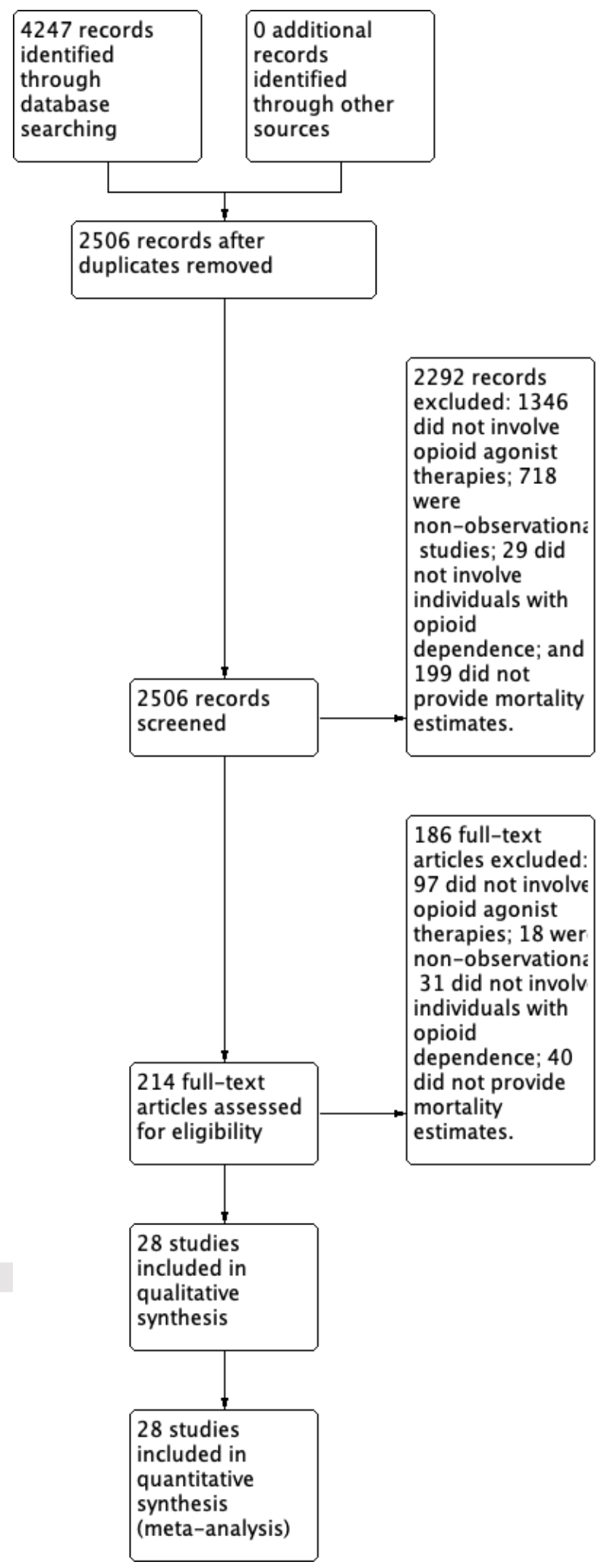

Figure 1. PRISMA Flow Diagram

This article is protected by copyright. All rights reserved. 
Studies

Brugal et al. 2005

Buster et al. 2002

Caplehorn et al. 1994

Caplehorn et al. 1996

Clausen et al. 2008

Cornish et al. 2010

Cousins et al. 2011

Cousins et al. 2016

Cushman 1997

Davoli et al. 2007

Degenhardt et al. 2009

Esteban et al. 2003

Evans et al. 2015

Fugelstad et al. 1995

Fugelstad et al. 1998

Fugelstad et al. 2007

Gearing et al. 1974

Gr.nbladh et al. 1990

Huang et al. 2011

Huang et al. 2013

Kimber et al. 2015

Nosyk et al. 2015

Peles et al. 2010

Risser et al. 2001

Russolillo et al. 2018

Scherbaum et al. 2002

Soyka et al. 2006

Subgroup Methadone $\left(\left.\right|^{\wedge} 2=9883 \%, P=0.000\right)$

Cornish et al. 2010b

Degenhardt et al. 2009b

Kimber et al. 2015b

Reece 2010b

Soyka et al. 2006b

Subgroup Buprenorphine $\left(\left.\right|^{\wedge} 2=5445 \%, P=0.06\right.$

Overall (I^2=9862 \%, P=0.000)
Estimate (95\% C.I.) Ev/Trt

$0.044(0.041,0.046) \quad 1006 / 23048$

$0.002(0.002,0.003) \quad 68 / 29730$

$0.011(0.008,0.014) \quad 47 / 4254$

$0.006(0.004,0.009) \quad 23 / 3796$

$0.018(0.015,0.020) \quad 136 / 7753$

$0.011(0.009,0.013) \quad 101 / 9417$

$0.004(0.003,0.005) \quad 64 / 14597$

$0.007(0.006,0.008) \quad 213 / 28895$

$0.020(0.014,0.026) \quad 39 / 1952$

$0.002(0.001,0.004) \quad 16 / 6749$

$0.010(0.010,0.010) 2158 / 217273$

$0.035(0.030,0.041) \quad 160 / 4516$

$0.014(0.013,0.015) 1011 / 73399$

$0.045(0.021,0.069) \quad 13 / 287$

$0.047(0.020,0.074) \quad 11 / 234$

$0.032(0.027,0.037) \quad 151 / 4665$

$0.009(0.008,0.011) \quad 143 / 15644$

$0.026(0.019,0.034) \quad 48 / 1825$

$0.016(0.010,0.021) \quad 31 / 1964$

$0.035(0.022,0.048) \quad 26 / 750$

$0.009(0.008,0.009) 1199 / 137057$

$0.053(0.047,0.059) \quad 295 / 5561$

$0.020(0.016,0.024) \quad 94 / 4712$

$0.022(0.018,0.027) \quad 95 / 4223$

$0.011(0.011,0.012) 1275 / 114244$

$0.025(0.016,0.033) \quad 32 / 1286$

$0.010(0.006,0.014) \quad 20 / 2013$

$0.017(0.015,0.020) 8475 / 719844$

$0.011(0.006,0.017) \quad 17 / 1491$

$0.008(0.007,0.009) \quad 169 / 21960$

$0.008(0.007,0.008) \quad 401 / 53175$

$0.005(0.004,0.007) \quad 43 / 8030$

$0.008(0.002,0.013) \quad 7 / 924$

$0.007(0.006,0.008) \quad 637 / 85580$

$0.016(0.014,0.017) 9112 / 805424$
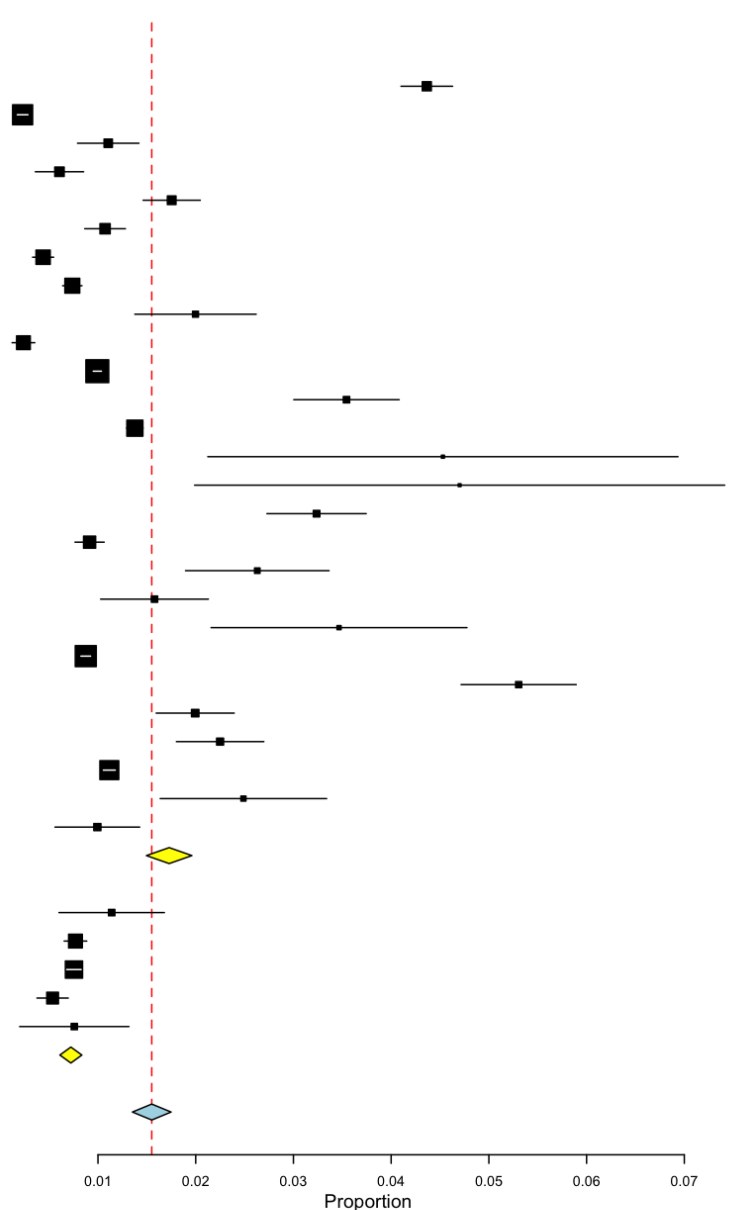

Figure 2. Forest plot of pooled, random-effects meta-analysis comparing all-cause crude mortality rates among individuals receiving methadone, buprenorphine, and overall.

This article is protected by copyright. All rights reserved. 


\section{Studies}

Brugal et al. 2005 Buster et al. 2002

Caplehorn

Clausen

Cousins et al. 2016

Cushman 1997

Davoli et al. 2007

Degenhardt et al. 2009

Esteban et al. 2003

Evans et al. 2015

Gearing et al. 1974

Gr.nbladh et al. 1990

Kimber et al. 2015

Peles et al. 2010

Risser et al. 2001

Russolillo et al. 2018

Scherbaum et al. 2002

Soyka et al. 2006

Kimber et al. 2015b

Soyka et al. 2006b

Subgroup Buprenorphine $\left(\left(^{\wedge} 2=0 \%, P=0.989\right)\right.$

Overall (I^2=9752\%, P=0.000)
Subgroup Methadone $\left(\left.\right|^{\wedge} 2=9774 \%, P=0.000\right)$

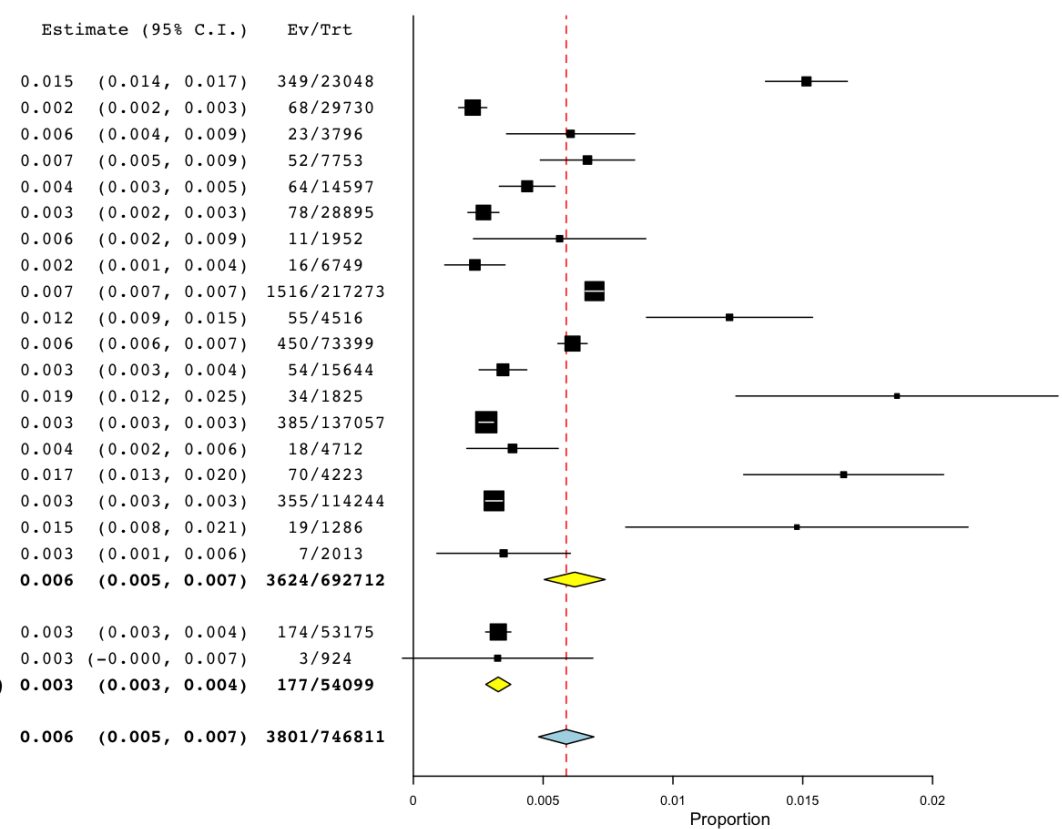

Figure 3. Forest plot of pooled, random-effects meta-analysis comparing overdose-specific crude mortality rates among individuals receiving methadone, buprenorphine, and overall.

Studies

Brugal et al. 2005

Buster et al. 2002

Caplehorn et al. 1994

Clausen et al. 2008

Cornish et al. 2010

Cousins et al. 2011

Cousins et al. 2016

Davoli et al. 2007

Degenhardt et al. 2009

Esteban et al. 2003

Evans et al. 2015

Fugelstad et al. 1995

Fugelstad et al. 1998

Fugelstad et al. 2007

Gearing et al. 1974

Gr.nbladh et al. 1990

Huang et al. 2011

Huang et al. 2013

Kimber et al. 2015

Nosyk et al. 2015

Risser et al. 2001

Russolillo et al. 2018

Scherbaum et al. 2002

Soyka et al. 2006

Subgroup Methadone $\left(I^{\wedge} 2=8494 \%, P=0.000\right)$

Cornish et al. 2010b

Degenhardt et al. 2009b

Kimber et al. 2015b

Reece 2010b

Soyka et al. 2006b

Overall $\left(I^{\wedge} 2=8359 \%, P=0.000\right)$

\begin{tabular}{|c|c|c|c|c|}
\hline Est & imate ( 95 & C.I.) & Ev/Trt & Ev/Ctrl \\
\hline 0.438 & $(0.363$ & $0.530)$ & $119 / 5400$ & $887 / 17649$ \\
\hline 0.946 & $(0.581$ & $1.543)$ & $42 / 18747$ & $26 / 10983$ \\
\hline 0.353 & $(0.180$ & $0.691)$ & $11 / 1975$ & $36 / 2279$ \\
\hline 0.235 & $(0.080$ & $0.691)$ & $4 / 1792$ & $19 / 2004$ \\
\hline 0.395 & $(0.278$ & $0.561)$ & $90 / 6450$ & $46 / 1303$ \\
\hline 0.353 & $(0.231$ & $0.540)$ & $30 / 5129$ & $71 / 4288$ \\
\hline 0.259 & (0.159, & $0.422)$ & $31 / 11441$ & $33 / 3156$ \\
\hline 0.324 & (0.248, & $0.423)$ & $115 / 22648$ & $98 / 6247$ \\
\hline 0.320 & (0.169, & $0.609)$ & $25 / 1655$ & $14 / 297$ \\
\hline 0.135 & $(0.050$ & $0.362)$ & $7 / 5751$ & $9 / 998$ \\
\hline 0.407 & $(0.371$ & $0.446)$ & $648 / 111538$ & $1510 / 1057$ \\
\hline 0.836 & (0.599, & $1.167)$ & $113 / 3351$ & $47 / 1165$ \\
\hline 0.366 & (0.310, & $0.432)$ & $163 / 25277$ & $848 / 48122$ \\
\hline 0.298 & $(0.102$ & $0.868)$ & $8 / 242$ & $5 / 45$ \\
\hline 0.564 & (0.171) & $1.856)$ & $7 / 177$ & $4 / 57$ \\
\hline 0.407 & $(0.298$ & $0.556)$ & $77 / 3354$ & $74 / 1311$ \\
\hline 0.269 & $(0.183$ & $0.396)$ & $110 / 14474$ & $33 / 1170$ \\
\hline 0.341 & $(0.189$ & $0.617)$ & $16 / 1085$ & $32 / 740$ \\
\hline 0.062 & (0.019, & $0.203)$ & $3 / 1245$ & $28 / 719$ \\
\hline 0.648 & (0.305, & $1.379)$ & $13 / 455$ & $13 / 295$ \\
\hline 0.557 & $(0.498$ & $0.624)$ & $636 / 91792$ & $563 / 45265$ \\
\hline 0.172 & (0.135, & $0.219)$ & $89 / 3979$ & $206 / 1582$ \\
\hline 0.147 & (0.099, & $0.220)$ & $42 / 3985$ & $52 / 727$ \\
\hline 0.268 & (0.171) & $0.419)$ & $26 / 2468$ & $69 / 1754$ \\
\hline 0.391 & (0.343, & $0.446)$ & $279 / 47682$ & $996 / 66562$ \\
\hline 0.199 & $(0.101$ & $0.392)$ & $18 / 1114$ & $14 / 172$ \\
\hline 0.536 & (0.223, & $1.288)$ & $9 / 1216$ & $11 / 797$ \\
\hline 0.350 & $(0.300$ & $0.408)$ & $2731 / 394422$ & $5744 / 32542$ \\
\hline 0.710 & $(0.272$ & $1.856)$ & $7 / 740$ & $10 / 751$ \\
\hline 0.906 & $(0.575$ & $1.429)$ & $21 / 2702$ & $148 / 17258$ \\
\hline 0.395 & $(0.311$ & $0.500)$ & $87 / 21936$ & $314 / 31239$ \\
\hline 0.463 & (0.144, & $1.495)$ & $3 / 1119$ & $40 / 6911$ \\
\hline 2.375 & (0.287, & 19.629) & $6 / 662$ & $1 / 262$ \\
\hline 0.630 & $(0.364$ & $1.092)$ & $124 / 27159$ & $513 / 56421$ \\
\hline
\end{tabular}

$0.372(0.322,0.430) \quad 2855 / 4215816257 / 381843$

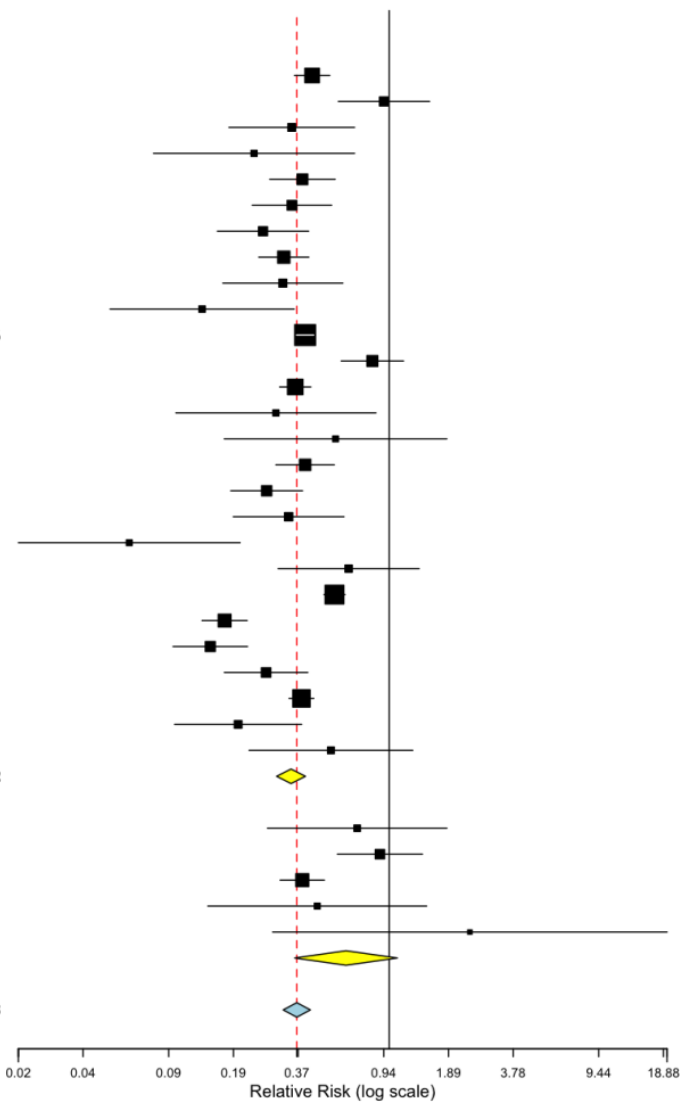

Figure 4. Forest plot of pooled, random-effects meta-analysis comparing all-cause crude mortality rate reduction (RR) among individuals in-versus-out of treatment with methadone, buprenorphine, and overall.

This article is protected by copyright. All rights reserved. 


\section{Studies}

Brugal et al. 2005

Buster et al. 2002

Caplehorn et al. 1996

Clausen et al. 2008

Cousins et al. 2011

Cousins et al. 2016

Cushman 1997

Davoli et al. 2007

Degenhardt et al. 2009

Esteban et al. 2003

Evans et al. 2015

Gearing et al. 1974

Gr.nbladh et al. 1990

Kimber et al. 2015

Peles et al. 2010

Risser et al. 2001

Russolillo et al. 2018

Scherbaum et al. 2002

Soyka et al. 2006

Subgroup Methadone $\left(\mathrm{I}^{\wedge} 2=8936 \%, \mathrm{P}=0.000\right)$

Kimber et al. 2015b

Soyka et al. 2006b

Subgroup Buprenorphine $\left(I^{\wedge} 2=5193 \%, P=0.149\right)$

Overall $\left(\left(^{\wedge} 2=8833 \%, P=0.000\right)\right.$
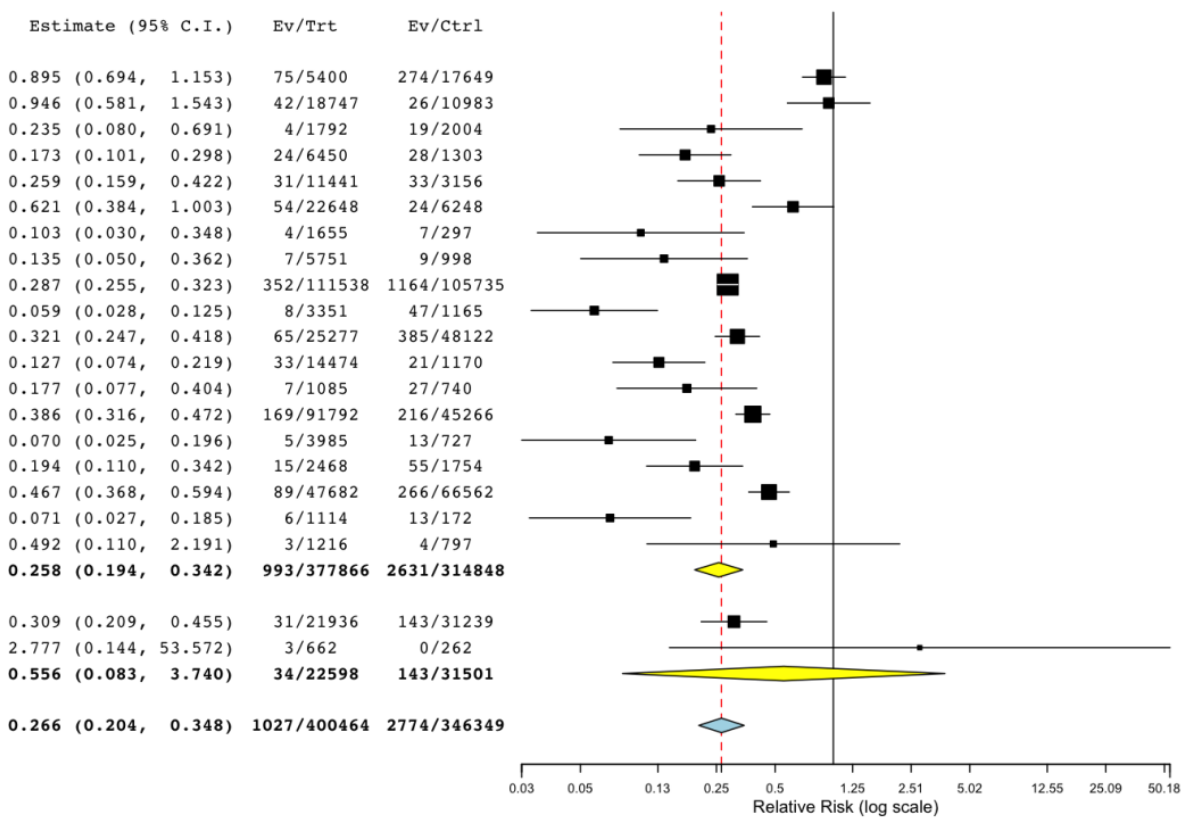

Figure 5. Forest plot of pooled, random-effects meta-analysis comparing overdose-specific crude mortality rate reduction (RR) among individuals in-versus-out of treatment with methadone, buprenorphine, and overall

\begin{tabular}{|c|c|c|c|c|}
\hline tudies & Estimate $195 \%$ & $5 \%$ C.I.) & Ev/Trt & Ev/Ctrl \\
\hline Buster et al. 2002 & $4.149(0.898,1$ & $19.169)$ & $9 / 1500$ & $2 / 1383$ \\
\hline Cornish et al. 2010 & $0.343(0.147$ & $0.800)$ & $7 / 465$ & $21 / 479$ \\
\hline Cousins et al. 2011 & $0.201(0.082$, & $0.494)$ & $8 / 880$ & $11 / 243$ \\
\hline Cousins et al. 2016 & $0.119(0.067$ & $0.214)$ & $15 / 3371$ & $44 / 1181$ \\
\hline Degenhardt et al. 2009 & $1.870(1.289$ & $2.712)$ & $94 / 2510$ & $38 / 1897$ \\
\hline Evans et al. 2015 & $0.134(0.079$, & $0.226)$ & $15 / 1950$ & $154 / 2673$ \\
\hline Huang et al. 2011 & $0.105(0.023$ & $0.472)$ & $2 / 1245$ & $11 / 719$ \\
\hline Kimber et al. 2015 & $0.502(0.312$, & $0.808)$ & $32 / 3344$ & $35 / 1836$ \\
\hline Nosyk et al. 2015 & $0.057(0.022$ & $0.151)$ & $4 / 100$ & $79 / 113$ \\
\hline Subgroup Methadone $\left(\left.\right|^{\wedge} 2=9382 \%, P=0.000\right)$ & $0.304(0.123$ & $0.753)$ & $186 / 15365$ & $395 / 10524$ \\
\hline Cornish et al. 2010b & $0.155(0.020$, & $1.234)$ & $1 / 81$ & $7 / 88$ \\
\hline Degenhardt et al. 2009b & $0.175(0.021$, & $1.494)$ & $1 / 406$ & $5 / 356$ \\
\hline Kimber et al. 2015b & $0.257(0.122$ & $0.543)$ & $9 / 2094$ & $28 / 1674$ \\
\hline Subgroup Buprenorphine $\left(I^{\wedge} 2=0 \%, P=0.869\right)$ & $0.235(0.120$, & $0.458)$ & $11 / 2581$ & $40 / 2118$ \\
\hline rall $(1 \times 2=91 / 1 \%, r$ & $0.279(0.130$ & $0.599)$ & 97/179 & 11 \\
\hline
\end{tabular}

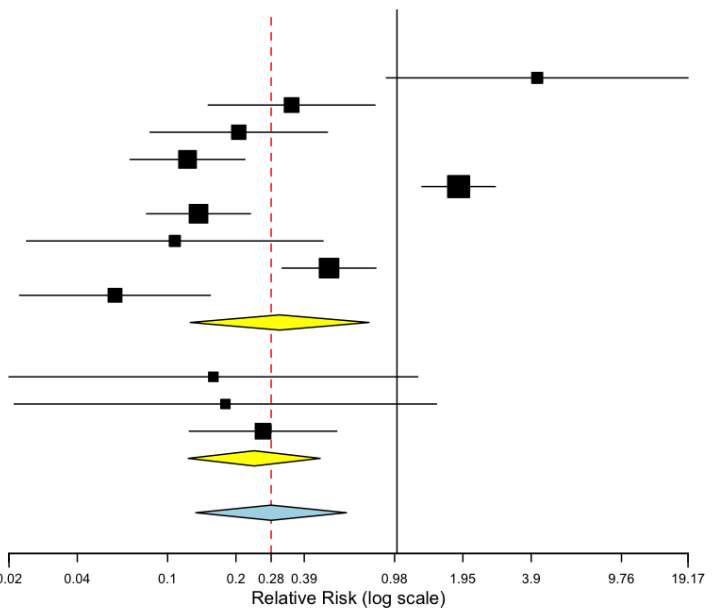

Figure 6. Forest plot of pooled, random-effects meta-analysis comparing all-cause crude mortality rate reduction (RR) among individuals in-versus-out of treatment with methadone, buprenorphine, and overall within the first four weeks of treatment.

This article is protected by copyright. All rights reserved. 


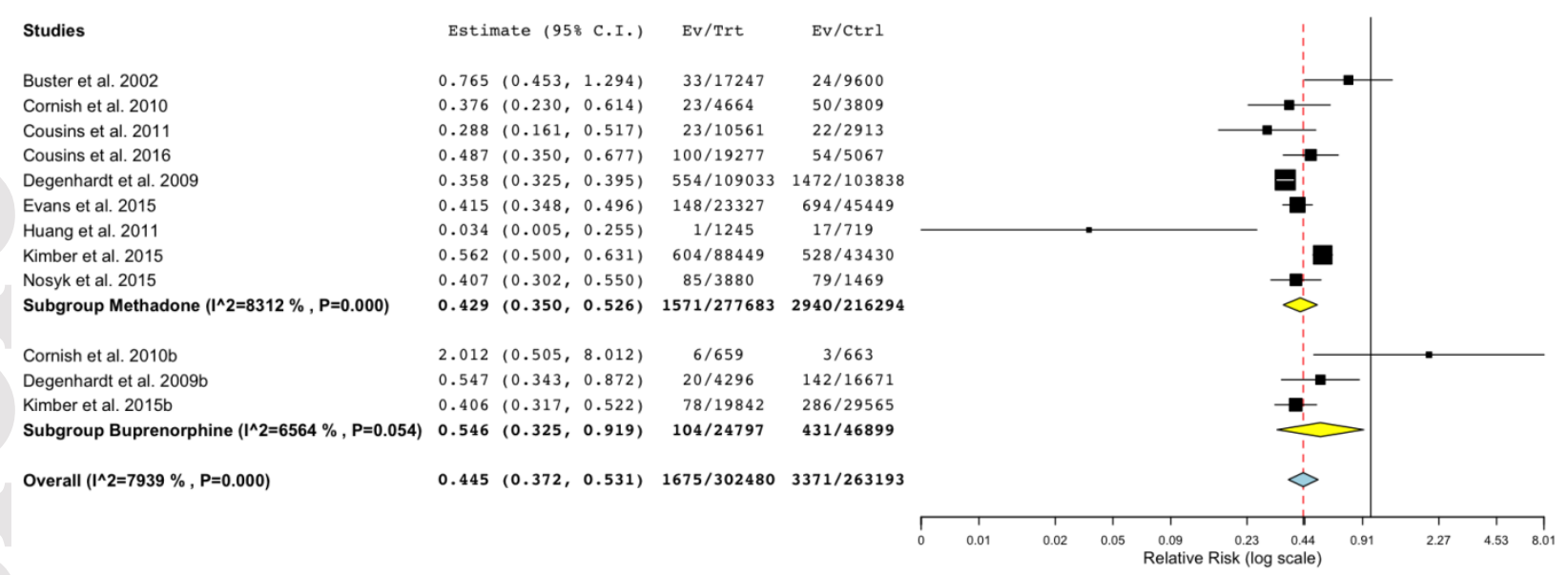

Figure 7. Forest plot of pooled, random-effects meta-analysis comparing overdose-specific crude mortality rate reduction (RR) among individuals in-versus-out of treatment with methadone, buprenorphine, and overall within the first four weeks of treatment.

Studies

Buster et al. 2002

Cousins et al. 2011

Cousins et al. 2016

Kimber et al. 2015

Subgroup Methadone $\left(I^{\wedge} 2=8256 \%, P=0.001\right)$

Kimber et al. 2015b

Subgroup Buprenorphine (।^2=NA , P=NA)

Overall $\left(\mathbf{I}^{\wedge} \mathbf{2}=\mathbf{8 2 0 6} \%, \mathrm{P}=\mathbf{0 . 0 0 0}\right)$
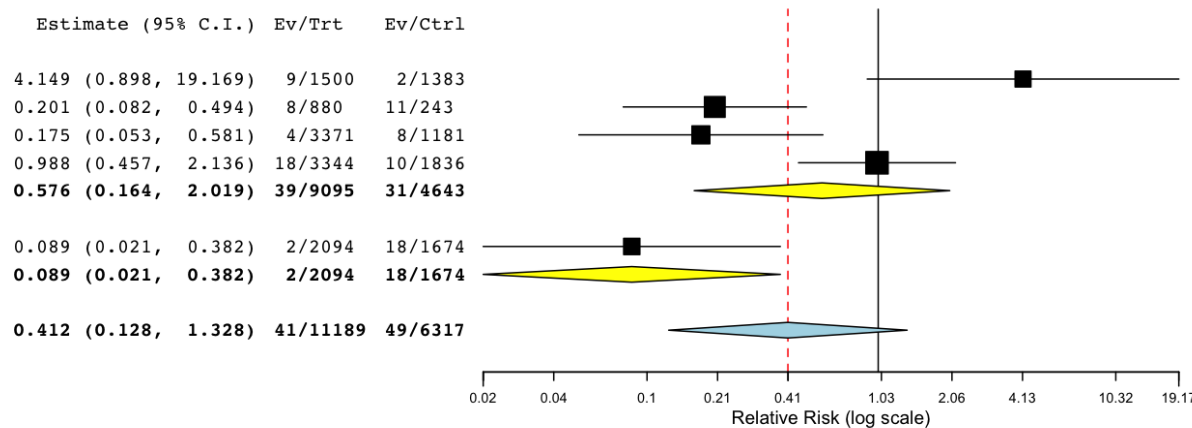

Figure 8. Forest plot of pooled, random-effects meta-analysis comparing overdose-specific crude mortality rate reduction (RR) among individuals in-versus-out of treatment with methadone, buprenorphine, and overall after four weeks of treatment.

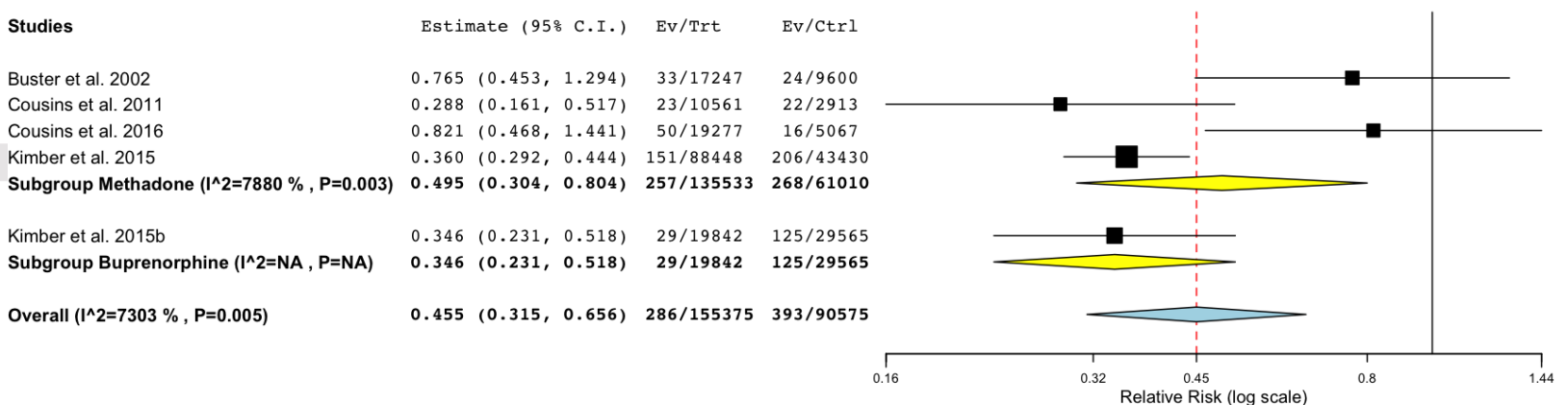

Figure 9. Forest plot of pooled, random-effects meta-analysis comparing overdose-specific crude mortality rate reduction (RR) among individuals in-versus-out of treatment with methadone, buprenorphine, and overall after four weeks of treatment.

This article is protected by copyright. All rights reserved. 
Table 1. Baseline population characteristics of cohort studies on mortality risk in people with opioid dependence during and after opioid agonist therapy with methadone or buprenorphine

\begin{tabular}{|c|c|c|c|c|c|c|c|}
\hline Study & Opioid Agonist & Country & PWID (\%) & HIV+ (\%) & Psychiatric Comorbidity (\%) & Male (\%) & Baseline Age (Years) \\
\hline Gearing et al. 1974 (33) & Methadone & United States & NA & 0 & 0 & 79 & 30.0 \\
\hline Cushman 1977 (34) & Methadone & United States & NA & 0 & 2.9 & 73 & 38.5 \\
\hline Grönbladh et al. 1990 (35) & Methadone & Sweden & NA & 0 & Unknown & 78.3 & 27.5 \\
\hline Caplehorn et al. 1994 (36) & Methadone & Australia & NA & 0 & Unknown & 72 & 23.4 \\
\hline Caplehorn et al. 1996 (37) & Methadone & Australia & NA & 0 & Unknown & 100 & 31.8 \\
\hline Fugelstad et al. 1995 (38) & Methadone & Sweden & 100 & 0 & 38.6 & 50 & 29.3 \\
\hline Fugelstad et al. 1998 (39) & Methadone & Sweden & 100 & 100 & Unknown & 71.5 & 28.0 \\
\hline Risser et al. 2001 (40) & Methadone & Austria & NA & 67.9 & Unknown & 77 & 32.6 \\
\hline Buster et al. 2002 (41) & Methadone & Netherlands & 34.7 & NA & 70 & 78 & 32.0 \\
\hline Scherbaum et al. 2002 (42) & Methadone & Germany & 100 & NA & Unknown & 79 & 30.0 \\
\hline Esteban et al. 2003 (43) & Methadone & Spain & 90 & NA & Unknown & 76.5 & 29.3 \\
\hline Brugal et al. 2005 (44) & Methadone & Spain & 59 & 66 & 65.9 & 68.4 & 34.8 \\
\hline Soyka et al. 2006 (76) & Methadone & Germany & NA & 51 & 13 & 80 & 31.5 \\
\hline Davoli et al. 2007 (46) & Methadone & Italy & 72 & 5.9 & Unknown & 100 & 38.2 \\
\hline Fugelstad et al. 2007 (47) & Methadone & Sweden & NA & 8 & Unknown & 67.6 & 39.6 \\
\hline Clausen et al. 2008 (48) & Methadone & Norway & 92.5 & 27.5 & Unknown & 64.8 & 29.6 \\
\hline Degenhardt et al. 2009 (49) & Methadone & Australia & NA & 3.5 & Unknown & 69.3 & 30.1 \\
\hline Cornish et al. 2010 (50) & Methadone & United Kingdom & NA & NA & 41.6 & 73.6 & 37.6 \\
\hline Peles et al. $2010(51)$ & Methadone & Israel & NA & NA & 32.9 & 64.8 & 30.0 \\
\hline Cousins et al. 2011 (52) & Methadone & Scotland & NA & 8.4 & Unknown & 88.0 & 37.0 \\
\hline Huang et al. 2011 (53) & Methadone & Taiwan & 100 & NA & 10.7 & 85.1 & 35.8 \\
\hline Huang et al. 2013 (54) & Methadone & Taiwan & 100 & 9 & 23.1 & 64.2 & 35.3 \\
\hline Evans et al. 2015 (55) & Methadone & United States & 55.2 & 18.3 & Unknown & 65.8 & 33.4 \\
\hline Kimber et al. 2015 (19) & Methadone & Australia & NA & NA & 22.8 & 68.7 & 30.5 \\
\hline Nosyk et al. 2015 (56) & Methadone & Canada & 100 & NA & 34.3 & 71.4 & 34.5 \\
\hline Cousins et al. 2016 (57) & Methadone & Scotland & NA & 100 & Unknown & 67.6 & 34.8 \\
\hline Russolillo et al. 2018 (58) & Methadone & Canada & NA & NA & Unknown & 64.8 & 29.6 \\
\hline Soyka et al. 2006 (76) & Buprenorphine & Germany & 92.5 & 3.5 & Unknown & 69.3 & 30.1 \\
\hline Degenhardt et al. 2009 (49) & Buprenorphine & Australia & NA & 3.5 & Unknown & 73 & 30.5 \\
\hline Cornish et al. 2010 (50) & Buprenorphine & United Kingdom & NA & 3.5 & Unknown & 70.7 & 32.5 \\
\hline Reece 2010 (59) & Buprenorphine & Australia & NA & NA & 0 & 79 & 30.0 \\
\hline Kimber et al. 2015 (19) & Buprenorphine & Australia & NA & NA & 2.9 & 73 & 38.5 \\
\hline
\end{tabular}

$P W I D=$ people who inject drugs (the proportion of the cohort that was actively injecting); HIV+ = proportion of the cohort that were HIV positive; NA=not available

This article is protected by copyright. All rights reserved. 
Table 2. Treatment delivery and follow-up features of cohort studies on mortality risk in people with opioid dependence during and after opioid agonist therapy with methadone or buprenorphine

\begin{tabular}{|c|c|c|c|c|c|c|c|c|c|}
\hline Study & $\begin{array}{l}\text { No of cohort } \\
\text { participants }\end{array}$ & $\begin{array}{l}\text { Average OAT } \\
\text { dose (mg/day) }\end{array}$ & $\begin{array}{l}\text { Inpatient } \\
\text { induction }(\%)\end{array}$ & $\begin{array}{l}\text { OAT } \\
\text { Provider }\end{array}$ & $\begin{array}{l}\text { Follow-up } \\
\text { period }\end{array}$ & $\begin{array}{l}\text { Average follow- } \\
\text { up (years) }\end{array}$ & $\begin{array}{l}\text { Loss to follow- } \\
\text { up }(\%)^{\S}\end{array}$ & $\begin{array}{l}\text { Mortality } \\
\text { outcome }\end{array}$ & $\begin{array}{l}\text { Quality } \\
\text { Score }^{\text {II }}\end{array}$ \\
\hline Gearing et al. 1974 (33) & 3000 & 100 & 17.6 & Specialist & $1965-1972$ & 6.2 & 4 & All, OD & 9 \\
\hline Cushman 1977 (34) & 547 & 100 & NA & Specialist & $1966-1975$ & 3.6 & 23.2 & All, OD & 6 \\
\hline Grönbladh et al. 1990 (35) & 166 & 75 & 100.0 & Specialist & $1967-1987$ & 11 & 0 & All, OD & 4 \\
\hline Caplehorn et al. 1994 (36) & 305 & 116 & 32.3 & Specialist & 1970-1990 & 13.9 & 14.4 & OD & 6 \\
\hline Caplehorn et al. 1996 (37) & 305 & 116 & 32.3 & Specialist & $1970-1990$ & 13.9 & 14.4 & All, OD & 6 \\
\hline Fugelstad et al. 1995 (38) & 135 & NA & 100.0 & Specialist & $1986-1990$ & 2.1 & 0 & All & 6 \\
\hline Fugelstad et al. 1998 (39) & 56 & 80 & 100.0 & Specialist & 1986-1993 & 4.2 & 0 & All & 6 \\
\hline Risser et al. 2001 (40) & 1729 & NA & NA & NA & $1995-1997$ & 3.0 & 0 & All, OD & 11 \\
\hline Buster et al. 2002 (41) & 5200 & 48 & 0.0 & Mixed & 1986-1998 & 5.7 & 0 & All, OD & 8 \\
\hline Scherbaum et al. $2002(42)$ & 244 & 47 & 0.0 & Specialist & 1988-1996 & 5.3 & 15.6 & All, OD & 7 \\
\hline Esteban et al. 2003 (43) & 1487 & NA & NA & NA & $1990-1997$ & 3.0 & 9.2 & All, OD & 11 \\
\hline Brugal et al. 2005 (44) & 5049 & 71 & NA & NA & $1992-1997$ & 4.6 & 0 & All, OD & 9 \\
\hline Soyka et al. 2006 (76) & 2013 & NA & NA & NA & 1993-1994 & 1.0 & 39.6 & All, OD & 11 \\
\hline Davoli et al. 2007 (46) & 5276 & NA & 0.0 & Specialist & 1998-2001 & 1.3 & 3.7 & OD & 11 \\
\hline Fugelstad et al. 2007 (47) & 679 & NA & 100.0 & Specialist & $1988-2000$ & 6.9 & 6.2 & All & 3 \\
\hline Clausen et al. 2008 (48) & 3229 & 112 & 0.0 & Mixed & $1997-2003$ & 2.4 & 0 & All, OD & 7 \\
\hline Degenhardt et al. 2009 (49) & 31846 & 70 & 0.0 & Mixed & $1985-2000$ & 6.8 & 0 & All & 17 \\
\hline Cornish et al. 2010 (50) & 4894 & 50 & 0.0 & GP & $1990-2005$ & 1.9 & 17.5 & All & 9 \\
\hline Peles et al. $2010(51)$ & 613 & 113 & 0.0 & Specialist & 1993-2008 & 7.7 & 0.8 & All, OD & 9 \\
\hline Cousins et al. 2011 (52) & 3162 & 60 & NA & NA & $1993-2004$ & 3.6 & 0 & OD & 11 \\
\hline Huang et al. 2011 (53) & 1982 & NA & NA & NA & $2007-2008$ & 1.0 & 0 & All & 14 \\
\hline Huang et al. 2013 (54) & 1616 & 48.3 & 100.0 & Specialist & $2006-2008$ & 0.5 & 38.9 & All & 13 \\
\hline Evans et al. 2015 (55) & 32322 & NA & 0.0 & Specialist & $2006-2010$ & 2.3 & 5 & All & 12 \\
\hline Kimber et al. 2015 (19) & 26064 & 70 & 0.0 & Mixed & $2001-2010$ & 5.3 & 0 & All, OD & 13 \\
\hline Nosyk et al. 2015 (56) & 1326 & NA & 0.0 & GP & $1996-2010$ & 4.2 & 7.9 & All & 13 \\
\hline Cousins et al. 2016 (57) & 6983 & 72 & 0.0 & GP & $2004-2010$ & 4.1 & 2 & All, OD & 11 \\
\hline Russolillo et al. 2018 (58) & 14530 & NA & NA & NA & $1998-2015$ & 6.9 & 0 & All, OD & 18 \\
\hline Soyka et al. $2006(76)$ & 662 & NA & NA & NA & $1993-1994$ & 1.0 & 39.6 & All, OD & 11 \\
\hline Degenhardt et al. 2009 (49) & 4494 & NA & 0.0 & Mixed & $2001-2006$ & 6.8 & 0 & All & 17 \\
\hline Cornish et al. $2010(50)$ & 1373 & 10 & 0.0 & GP & $1990-2005$ & 1.1 & 10.3 & All & 9 \\
\hline Reece $2010(59)$ & 2518 & NA & 0.0 & GP & $2000-2007$ & 3.2 & 1.2 & All & 13 \\
\hline Kimber et al. 2015 (19) & 11940 & 12 & 0.0 & Mixed & $2001-2010$ & 4.5 & 0 & All, OD & 13 \\
\hline
\end{tabular}

$N A=$ not available; OAT=opioid agonist treatment $;{ }^{\dagger}$ Participants receiving opioid agonist treatment at least once during study period. ${ }^{*}$ Average follow-up

from start of opioid agonist treatment combining subsequent periods in and out of treatment. ${ }^{\S}$ Percentage loss to follow-up before end of study period or death. If not otherwise specified, complete case ascertainment assumed for studies based on population mortality registries. ${ }^{\text {II }}$ Quality assessment score ranging from 0 (lowest quality) to 19 (highest quality).

This article is protected by copyright. All rights reserved. 
Table 3. Bivariate meta-regression analysis of moderators for all-cause crude mortality rate reduction in-versus-out-of-treatment with opioid agonist therapy

\begin{tabular}{|c|c|c|c|}
\hline Moderator & Coefficient & Standard Error & p-value \\
\hline All-cause & & & \\
\hline Pub. Year & 0.003 & 0.009 & 0.746 \\
\hline HIV+(\%) & 0.001 & 0.004 & 0.741 \\
\hline Psych (\%) & -0.003 & $0 . .06$ & 0.626 \\
\hline Men (\%) & -0.007 & 0.010 & 0.472 \\
\hline Avg. OAT dose & -0.006 & 0.003 & 0.053 \\
\hline OAT Provider & -0.933 & 0.155 & $<\mathbf{0 . 0 0 1}$ \\
\hline PWID (\%) & -0.011 & 0.008 & 0.156 \\
\hline Region & -0.979 & 0.116 & $<\mathbf{0 . 0 0 1}$ \\
\hline Country & -0.552 & 0.176 & $\mathbf{0 . 0 0 2}$ \\
\hline Quality Score & 0.015 & 0.024 & 0.515 \\
\hline Mean Age & -0.020 & 0.023 & 0.391 \\
\hline Opioid Agonist & 0.581 & 0.269 & $\mathbf{0 . 0 3 1}$ \\
\hline Overdose-specific & & & \\
\hline Pub. Year & 0.028 & 0.14 & $\mathbf{0 . 0 4 5}$ \\
\hline HIV+(\%) & 0.003 & 0.012 & 0.791 \\
\hline Psych (\%) & 0.000 & 0.012 & 0.989 \\
\hline Men (\%) & -0.049 & 0.032 & 0.123 \\
\hline Avg. OAT dose & -0.011 & 0.007 & 0.105 \\
\hline OAT Provider & -1.135 & 0.260 & $<\mathbf{0 . 0 0 1}$ \\
\hline PWID (\%) & -0.038 & 0.010 & $<\mathbf{0 . 0 0 1}$ \\
\hline Region & -1.383 & 0.227 & $<\mathbf{0 . 0 0 1}$ \\
\hline Country & -1.175 & 0.376 & $\mathbf{0 . 0 0 2}$ \\
\hline Quality Score & 0.064 & 0.048 & 0.187 \\
\hline Mean Age & -0.016 & 0.048 & 0.740 \\
\hline Opioid Agonist & 0.575 & 0.695 & 0.408 \\
\hline
\end{tabular}

This article is protected by copyright. All rights reserved. 
Appendix 1. Search Strategy

MEDLINE: inception to June 11, 2019

\begin{tabular}{|c|l|l|}
\hline Order & Search Term & Results \\
\hline 1. & exp Methadone/ & 11975 \\
\hline 2. & $\begin{array}{l}\text { buprenorphine.mp. or exp Buprenorphine, Naloxone Drug } \\
\text { Combination/ or exp Buprenorphine/ }\end{array}$ & 6980 \\
\hline 3. & exp Opiate Substitution Treatment/ or opioid agonist therapy.mp. & 2601 \\
\hline 4. & exp Mortality/ or mortality.mp. & 1174420 \\
\hline 5. & exp Drug Overdose/ or overdose.mp. & 20960 \\
\hline 6. & 1 or 2 or 3 & 18276 \\
\hline 7. & 4 or 5 & 1191797 \\
\hline 8. & 6 and 7 & 1385 \\
\hline 9. 1 & Limit 9 to English and Humans & $\mathbf{1 1 0 2}$ \\
\hline
\end{tabular}

EMBASE: inception to June 11, 2019

\begin{tabular}{|c|l|l|}
\hline Order & Search Term & Results \\
\hline 1. & exp methadone treatment/ or methadone.mp. or exp methadone/ & 34543 \\
\hline 2. & $\begin{array}{l}\text { buprenorphine.mp. or exp buprenorphine plus naloxone/ or exp } \\
\text { buprenorphine/ }\end{array}$ & 17718 \\
\hline 3. & $\begin{array}{l}\text { opioid agonist therapy.mp. or exp hydromorphone/ or exp } \\
\text { levacetylmethadol/ }\end{array}$ & 699 \\
\hline 4. & exp mortality/ or mortality.mp & 1413186 \\
\hline 5. & exp drug overdose/ or opioid overdose.mp. & 25869 \\
\hline 6. & 1 or 2 or 3 & 45658 \\
\hline 7. & 4 or 5 & 1436157 \\
\hline 8. & 6 and 7 & 3481 \\
\hline 9. & exp cohort analysis/ or cohort.mp. & 902712 \\
\hline $\mathbf{1 0 .}$ & $\mathbf{8}$ and 9 & $\mathbf{3 1 8}$ \\
\hline
\end{tabular}

PsycINFO: inception to June 11, 2019

\begin{tabular}{|c|l|l|}
\hline Order & Search Term & Results \\
\hline 1. & exp Methadone Maintenance/ or exp Methadone/ or methadone.mp. & 7858 \\
\hline 2. & buprenorphine.mp. or exp Buprenorphine/ & 2780 \\
\hline 3. & opioid agonist.mp. & 1048 \\
\hline 4. & 1 or 2 or 3 & 10078 \\
\hline 5. & mortality.mp. or exp "Death and Dying"/ & 60500 \\
\hline 6. & exp Drug Overdoses/ or opioid overdose.mp. & 1774 \\
\hline 7. & 5 or 6 & 61836 \\
\hline 8. & $\mathbf{4}$ and 7 & $\mathbf{5 3 4}$ \\
\hline
\end{tabular}

CINAHL: inception to June 11, 2019

\begin{tabular}{|c|l|l|}
\hline Order & Search Term & Results \\
\hline 1. & (MH "Methadone") OR "methadone" & 5696 \\
\hline 2. & (MH "Buprenorphine") OR "buprenorphine" & 3494 \\
\hline
\end{tabular}

This article is protected by copyright. All rights reserved. 


\begin{tabular}{|l|l|l|}
\hline 3. & "opioid agonist therapy" & 157 \\
\hline 4. & (MH "Mortality") OR "mortality" & 246,139 \\
\hline 5. & (MH "Overdose") OR "opioid overdose" & 6,086 \\
\hline 6. & 1 or 2 or 3 & 7,943 \\
\hline 7. & 4 or 5 & 250,896 \\
\hline 8. & 6 and 7 & $\mathbf{7 3 1}$ \\
\hline
\end{tabular}

Cochrane CENTRAL Library: inception to June 11, 2019

\begin{tabular}{|c|l|l|}
\hline Order & Search Term & Results \\
\hline 1. & MeSH descriptor: [Analgesics, Opioid] explode all trees & 6907 \\
\hline 2. & MeSH descriptor: [Methadone] explode all trees & 1163 \\
\hline 3. & MeSH descriptor: [Buprenorphine] explode all trees & 1017 \\
\hline 4. & MeSH descriptor: [Mortality] explode all trees & 12668 \\
\hline 5. & (1 or 2 or 3) and 4 & $\mathbf{1 2}$ \\
\hline
\end{tabular}

ProQuest Dissertations \& Theses: inception to June 11, 2019

\begin{tabular}{|c|l|l|}
\hline Order & Search Term & Results \\
\hline 1. & $\begin{array}{l}\text { ("methadone" OR "buprenorphine") AND "mortality" AND } \\
\text { "cohort" AND ("opioid dependence" OR "opioid use disorder")/ }\end{array}$ & 430 \\
\hline
\end{tabular}

Allied and Complementary Medicine: inception to June 11, 2019

\begin{tabular}{|c|l|l|}
\hline Order & Search Term & Results \\
\hline 1. & Methadone/ or analgesics opioid/ or methadone.mp. & 474 \\
\hline 2. & Buprenorphine/ or buprenorphine.mp. & 49 \\
\hline 3. & 1 or 2 & 499 \\
\hline 4. & Mortality/ or mortality.mp. & 3086 \\
\hline 5. & $\mathbf{3}$ and 4 & $\mathbf{1 4}$ \\
\hline
\end{tabular}

Web of Science: inception to June 11, 2019

\begin{tabular}{|c|l|l|}
\hline Order & Search Term & Results \\
\hline 1. & (methadone or buprenorphine or opioid agonist therapy) & 22,814 \\
\hline 2. & (mortality) & 883,467 \\
\hline 3. & $\mathbf{1}$ and 2 & $\mathbf{1 , 1 0 6}$ \\
\hline
\end{tabular}

This article is protected by copyright. All rights reserved. 
Appendix 2. Reporting checklist for meta-analysis of observational studies based on the MOOSE guidelines.

\begin{tabular}{|c|c|c|}
\hline Segment & Reporting Item & Page Number \\
\hline Title & $\begin{array}{l}\text { Identify the study as a meta-analysis of observational } \\
\text { research }\end{array}$ & 1 \\
\hline Abstract & $\begin{array}{l}\text { Provide a structured summary including, as applicable: } \\
\text { background; objectives; data sources; study eligibility } \\
\text { criteria, participants, and interventions; study appraisal } \\
\text { and synthesis methods; results; limitations; conclusions } \\
\text { and implications of key findings; systematic review } \\
\text { registration number (From PRISMA checklist) }\end{array}$ & 2 \\
\hline \multirow{6}{*}{ Background } & Problem definition & 3 \\
\hline & Hypothesis statement & 4 \\
\hline & Description of study outcomes & 4 \\
\hline & Type of exposure or intervention used & 5 \\
\hline & Type of study designs used & 5 \\
\hline & Study population & 5 \\
\hline \multirow{17}{*}{ Methods } & $\begin{array}{l}\text { Qualifications of searchers (e.g., librarians and } \\
\text { investigators) }\end{array}$ & 5 \\
\hline & $\begin{array}{l}\text { Search strategy, including time period included in the } \\
\text { synthesis and keywords }\end{array}$ & 5 \\
\hline & $\begin{array}{l}\text { Effort to include all available studies, including contact } \\
\text { with authors }\end{array}$ & 5 \\
\hline & Databases and registries searched & 5 \\
\hline & $\begin{array}{l}\text { Search software used, name and version, including } \\
\text { special features used (e.g., explosion) }\end{array}$ & 5 \\
\hline & $\begin{array}{l}\text { Use of hand searching (e.g., reference lists of obtained } \\
\text { articles) }\end{array}$ & 5 \\
\hline & $\begin{array}{l}\text { List of citations located and those excluded, including } \\
\text { justification }\end{array}$ & 5 \\
\hline & $\begin{array}{l}\text { Method of addressing articles published in languages } \\
\text { other than English }\end{array}$ & 5 \\
\hline & Method of handling abstracts and unpublished studies & 5 \\
\hline & Description of any contact with authors & 5 \\
\hline & $\begin{array}{l}\text { Description of relevance or appropriateness of studies } \\
\text { gathered for assessing the hypothesis to be tested }\end{array}$ & 5 \\
\hline & $\begin{array}{l}\text { Rationale for the selection and coding of data (e.g., } \\
\text { sound clinical principles or convenience) }\end{array}$ & 6 \\
\hline & $\begin{array}{l}\text { Documentation of how data were classified and coded } \\
\text { (e.g., multiple raters, blinding, and interrater reliability) }\end{array}$ & 6 \\
\hline & $\begin{array}{l}\text { Assessment of confounding (e.g., comparability of cases } \\
\text { and controls in studies where appropriate) }\end{array}$ & 6 \\
\hline & $\begin{array}{l}\text { Assessment of study quality, including blinding of } \\
\text { quality assessors; stratification or regression on possible } \\
\text { predictors of study results }\end{array}$ & 6 \\
\hline & Assessment of heterogeneity & 6 \\
\hline & $\begin{array}{l}\text { Description of statistical methods (e.g., complete } \\
\text { description of fixed or random effects models, }\end{array}$ & 6 \\
\hline
\end{tabular}

This article is protected by copyright. All rights reserved. 


\begin{tabular}{|l|l|l|}
\hline \multirow{5}{*}{} & $\begin{array}{l}\text { justification of whether the chosen models account for } \\
\text { predictors of study results, dose-response models, or } \\
\text { cumulative meta-analysis) in sufficient detail to be } \\
\text { replicated }\end{array}$ & \\
\cline { 2 - 3 } Results & Provision of appropriate tables and graphics & 6 \\
\hline & $\begin{array}{l}\text { Graphic summarizing individual study estimates and } \\
\text { overall estimate }\end{array}$ & $8-9$ \\
\cline { 2 - 3 } & $\begin{array}{l}\text { Table giving descriptive information for each study } \\
\text { included }\end{array}$ & $8-9$ \\
\cline { 2 - 3 } & Results of sensitivity testing (e.g., subgroup analysis) & $8-9$ \\
\cline { 2 - 3 } & Indication of statistical uncertainty of findings & $8-9$ \\
\hline \multirow{5}{*}{ Qiscussion } & Quantitative assessment of bias (e.g. publication bias) & $22-23$ \\
\cline { 2 - 3 } & $\begin{array}{l}\text { Justification for exclusion (e.g., exclusion of non- } \\
\text { English-language citations) }\end{array}$ & $10-13$ \\
\cline { 2 - 3 } & Assessment of quality of included studies & $10-13$ \\
\hline Conclusion & $\begin{array}{l}\text { Consideration of alternative explanations for observed } \\
\text { results }\end{array}$ & $10-13$ \\
\cline { 2 - 3 } & $\begin{array}{l}\text { Generalization of the conclusions (i.e., appropriate for } \\
\text { the data presented and within the domain of the } \\
\text { literature review) }\end{array}$ & $10-13$ \\
\cline { 2 - 3 } & Guidelines for future research & $10-13$ \\
\cline { 2 - 3 } & Disclosure of funding source & $10-13$ \\
\hline
\end{tabular}

This article is protected by copyright. All rights reserved. 
Appendix 3. Quality Assessment Scores

\begin{tabular}{|c|c|c|c|c|c|c|c|c|c|c|}
\hline Study & $\begin{array}{ll}\text { Case } & \\
& \begin{array}{l}\text { Ascertainm } \\
\text { ent }\end{array} \\
\end{array}$ & Measurement & Diagnosis & Estimate & $\begin{array}{l}\text { Numerator \& } \\
\text { Denominator }\end{array}$ & $\begin{array}{l}\text { Numerator \& } \\
\text { Denominator } \\
\text { Epoch }\end{array}$ & Completeness & Representativeness & Age/Sex & Quality \\
\hline $\begin{array}{c}\text { Gearing et al. } \\
1974 \\
(33)\end{array}$ & 2 & 2 & 0 & 1 & 1 & 1 & 0 & 1 & 1 & 9 \\
\hline $\begin{array}{c}\text { Cushman } 1977 \\
\text { (34) }\end{array}$ & 1 & 1 & 0 & 1 & 1 & 0 & 0 & 1 & 1 & 6 \\
\hline $\begin{array}{c}\text { Grönbladh et } \\
\text { al. } 1990 \\
(35)\end{array}$ & 0 & 0 & 0 & 0 & 1 & 1 & 0 & 1 & 1 & 4 \\
\hline $\begin{array}{c}\text { Caplehorn et } \\
\text { al. } 1994 \\
(36)\end{array}$ & 1 & 0 & 0 & 1 & 1 & 1 & 0 & 1 & 1 & 6 \\
\hline $\begin{array}{c}\text { Caplehorn et } \\
\text { al. } 1996 \\
(37)\end{array}$ & 1 & 1 & 1 & 0 & 0 & 0 & 1 & 1 & 1 & 6 \\
\hline $\begin{array}{c}\text { Fugelstad et al. } \\
\begin{array}{c}1995 \\
(38)\end{array}\end{array}$ & 1 & 1 & 1 & 1 & 1 & 1 & 0 & 0 & 0 & 6 \\
\hline $\begin{array}{c}\text { Fugelstad et al. } \\
1998 \\
(39)\end{array}$ & 0 & 0 & 0 & 1 & 1 & 1 & 2 & 0 & 1 & 6 \\
\hline $\begin{array}{r}\text { Risser et al. } \\
2001 \\
(40)\end{array}$ & 1 & 1 & 2 & 1 & 1 & 1 & 2 & 1 & 1 & 11 \\
\hline $\begin{array}{c}\text { Buster et al. } \\
2002 \\
(41)\end{array}$ & 1 & 1 & 1 & 1 & 1 & 1 & 1 & 1 & 0 & 8 \\
\hline $\begin{array}{r}\text { Scherbaum et } \\
\text { al. } 2002 \\
(42)\end{array}$ & 1 & 1 & 1 & 1 & 0 & 1 & 1 & 0 & 1 & 7 \\
\hline $\begin{array}{c}\text { Esteban et al. } \\
\mathbf{2 0 0 3} \\
(\mathbf{4 3})\end{array}$ & 1 & 0 & 1 & 2 & 2 & 1 & 2 & 1 & 1 & 11 \\
\hline $\begin{array}{c}\text { Brugal et al. } \\
\mathbf{2 0 0 5} \\
(\mathbf{4 4})\end{array}$ & 2 & 1 & 2 & 0 & 0 & 0 & 1 & 2 & 1 & 9 \\
\hline $\begin{array}{r}\text { Soyka et al. } \\
2006\end{array}$ & 1 & 1 & 1 & 2 & 2 & 1 & 1 & 1 & 1 & 11 \\
\hline
\end{tabular}

This article is protected by copyright. All rights reserved. 


\begin{tabular}{|c|c|c|c|c|c|c|c|c|c|c|}
\hline (76) & & & & & & & & & & \\
\hline $\begin{array}{c}\text { Davoli et al. } \\
2007 \\
(46)\end{array}$ & 1 & 1 & 1 & 2 & 2 & 1 & 1 & 1 & 1 & 11 \\
\hline $\begin{array}{c}\text { Fugelstad et al. } \\
2007 \\
(47)\end{array}$ & 0 & 0 & 1 & 0 & 0 & 0 & 1 & 0 & 1 & 3 \\
\hline $\begin{array}{c}\text { Clausen et al. } \\
\mathbf{2 0 0 8} \\
(\mathbf{4 8})\end{array}$ & 0 & 1 & 1 & 1 & 1 & 1 & 1 & 0 & 1 & 7 \\
\hline $\begin{array}{l}\text { Degenhardt et } \\
\text { al. } 2009 \\
(49)\end{array}$ & 3 & 2 & 2 & 2 & 2 & 1 & 1 & 3 & 1 & 17 \\
\hline $\begin{array}{c}\text { Cornish et al. } \\
\text { 2010 } \\
(\mathbf{5 0})\end{array}$ & 0 & 0 & 1 & 2 & 2 & 1 & 2 & 0 & 1 & 9 \\
\hline $\begin{array}{r}\text { Peles et al. } \\
2010 \\
(51)\end{array}$ & 1 & 1 & 1 & 1 & 1 & 1 & 1 & 1 & 1 & 9 \\
\hline $\begin{array}{c}\text { Cousins et al. } \\
\mathbf{2 0 1 1} \\
(\mathbf{5 2})\end{array}$ & 2 & 1 & 1 & 1 & 1 & 1 & 1 & 2 & 1 & 11 \\
\hline $\begin{array}{c}\text { Huang et al. } \\
\mathbf{2 0 1 1} \\
(\mathbf{5 3})\end{array}$ & 2 & 0 & 2 & 2 & 2 & 1 & 2 & 2 & 1 & 14 \\
\hline $\begin{array}{c}\text { Huang et al. } \\
2013 \\
(54)\end{array}$ & 2 & 2 & 2 & 1 & 1 & 1 & 1 & 2 & 1 & 13 \\
\hline $\begin{array}{c}\text { Evans et al. } \\
\mathbf{2 0 1 5} \\
(\mathbf{5 5})\end{array}$ & 2 & 2 & 1 & 1 & 1 & 0 & 2 & 2 & 1 & 12 \\
\hline $\begin{array}{c}\text { Kimber et al. } \\
2015 \\
(19)\end{array}$ & 1 & 2 & 1 & 1 & 1 & 1 & 2 & 3 & 1 & 13 \\
\hline $\begin{array}{c}\text { Nosyk et al. } \\
2015 \\
(56)\end{array}$ & 3 & 2 & 2 & 1 & 1 & 1 & 1 & 1 & 1 & 13 \\
\hline $\begin{array}{c}\text { Cousins et al. } \\
\mathbf{2 0 1 6} \\
(\mathbf{5 7})\end{array}$ & 2 & 1 & 1 & 1 & 1 & 1 & 1 & 2 & 1 & 11 \\
\hline $\begin{array}{c}\text { Russolillo et al. } \\
2018\end{array}$ & 3 & 2 & 1 & 2 & 2 & 1 & 3 & 3 & 1 & 18 \\
\hline
\end{tabular}

This article is protected by copyright. All rights reserved. 
Soyka et al.

2006

(76)

Degenhardt et al. 2009

Cornish

2010

Reece 2010

Kimber et al.

2015

(19)

\begin{tabular}{|l|l|}
\hline 1 & 1 \\
\hline 3 & 2 \\
\hline 0 & 0 \\
\hline 2 & 0 \\
\hline 1 & 2 \\
\hline
\end{tabular}

\begin{tabular}{|l|l|}
1 \\
2 \\
1 \\
\hline 1 \\
\hline
\end{tabular}

2

2

2

2

\begin{tabular}{|l|l|l|l|l|}
\hline 1 & 1 & 1 & 1 & 11 \\
\hline 1 & 1 & 3 & 1 & 17 \\
\hline 1 & 2 & 0 & 1 & 9 \\
\hline 1 & 2 & 2 & 1 & 13 \\
\hline 1 & 2 & 3 & 1 & 13 \\
\hline
\end{tabular}

This article is protected by copyright. All rights reserved. 


\section{Quality Assessment Index}

1. Case Ascertainment (/3)

a. Were the results on crude mortality clearly specified?

i. Yes: $1 / 1$

ii. No: $0 / 1$

b. Were the results on overdose mortality clearly specified?

i. Yes: $1 / 1$

ii. No: $0 / 1$

c. Were the timelines with respect to opioid agonist therapy clearly specified?

i. Yes: $1 / 1$

ii. No: $0 / 1$

2. Measurement (/2)

a. Was a measurement instrument used to assess exposure of interest?

i. Yes: $1 / 1$

ii. No: $0 / 1$

b. Was a measurement instrument used to assess outcome of interest?

i. Yes: $1 / 1$

ii. No: $0 / 1$

3. Diagnosis (/2)

a. Were eligibility criteria for inclusion in the cohort described in detail?

i. Fully described: $2 / 2$

ii. Partially described: $1 / 2$

iii. No: $0 / 2$

4. Estimate (/2)

a. Was the mortality rate clearly reported?

i. Yes: $1 / 1$

ii. No: $0 / 1$

b. Were the time-dependent mortality rates (in/out of opioid agonist therapy) clearly reported?

i. Yes: $1 / 1$

ii. No: $0 / 1$

5. Numerator \& Denominator $(/ 2)$

a. Were the person years of follow-up reported?

i. Yes: $1 / 1$

ii. No: $0 / 1$

b. Were the number of deaths (overall and overdose-specific) reported?

i. Yes: $1 / 1$

ii. No: $0 / 1$

6. Numerator \& Denominator Epoch (/1)

a. Were the mortality estimates and timelines for opioid agonist therapy for the same cohort of individuals (i.e., were the same timelines used)?

i. Yes: $1 / 1$

ii. No: $0 / 1$

7. Completeness (/3)

a. To what extent did the study have complete follow-up for its participants?

i. $\geq 70 \%: 3 / 3$

ii. $>50 \%: 2 / 3$

iii. Reported but $<50 \%$ : $1 / 3$

iv. Not reported: $0 / 3$

8. Representativeness (/3)

This article is protected by copyright. All rights reserved. 
a. Nationally/internationally representative sample: $3 / 3$

b. Regionally representative (e.g., within one province or state): $2 / 3$

c. Locally representative (e.g., single hospital/center): 1/3

d. Not described: $0 / 3$

9. Age \& Sex (/1)

a. Were the potential confounding effects of age and sex were taken into account by the study?

i. Yes: $1 / 1$

ii. No: $0 / 1$

10. Quality

a. Global quality score obtained by summing the scores from other domains (019).

This article is protected by copyright. All rights reserved. 
Appendix 4. Assessment of Publication Bias for All-Cause Mortality Rates

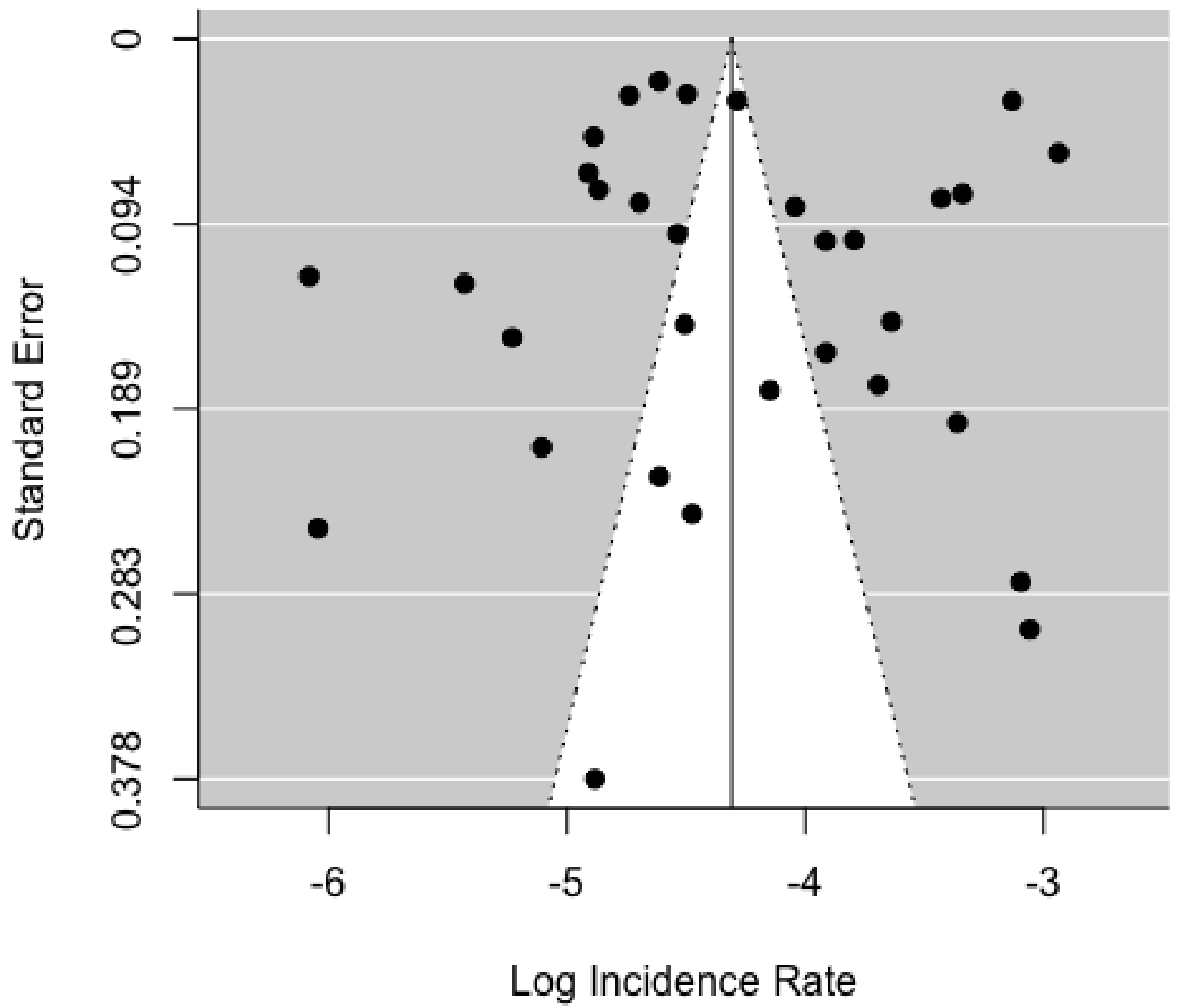

- Funnel plot for risk of publication bias in crude all-cause mortality rate appeared grossly symmetric.

- Rank Correlation Test for Funnel Plot Asymmetry

○ Kendall's tau $=0.1008, p=0.4299$

- Regression Test for Funnel Plot Asymmetry

○ model: mixed-effects meta-regression model

o predictor: standard error

$\circ$ test for funnel plot asymmetry: $\mathrm{z}=-0.1516, \mathrm{p}=0.8795$

- Estimated number of missing studies on the right side: $0(\mathrm{SE}=3.3308)$

- Random-Effects Model ( $\mathrm{k}=32$; $\mathrm{tau}^{\wedge} 2$ estimator: REML)

$\bigcirc \operatorname{tau}^{2}$ (estimated amount of total heterogeneity): $0.6506(\mathrm{SE}=0.1713)$

- tau (square root of estimated tau^2 value): 0.8066

- $\mathrm{I}^{2}$ (total heterogeneity / total variability): $99.41 \%$

- $\mathrm{H}^{2}$ (total variability / sampling variability): 168.71

This article is protected by copyright. All rights reserved. 
Appendix 5. Assessment of Publication Bias for Overdose-Specific Mortality Rate

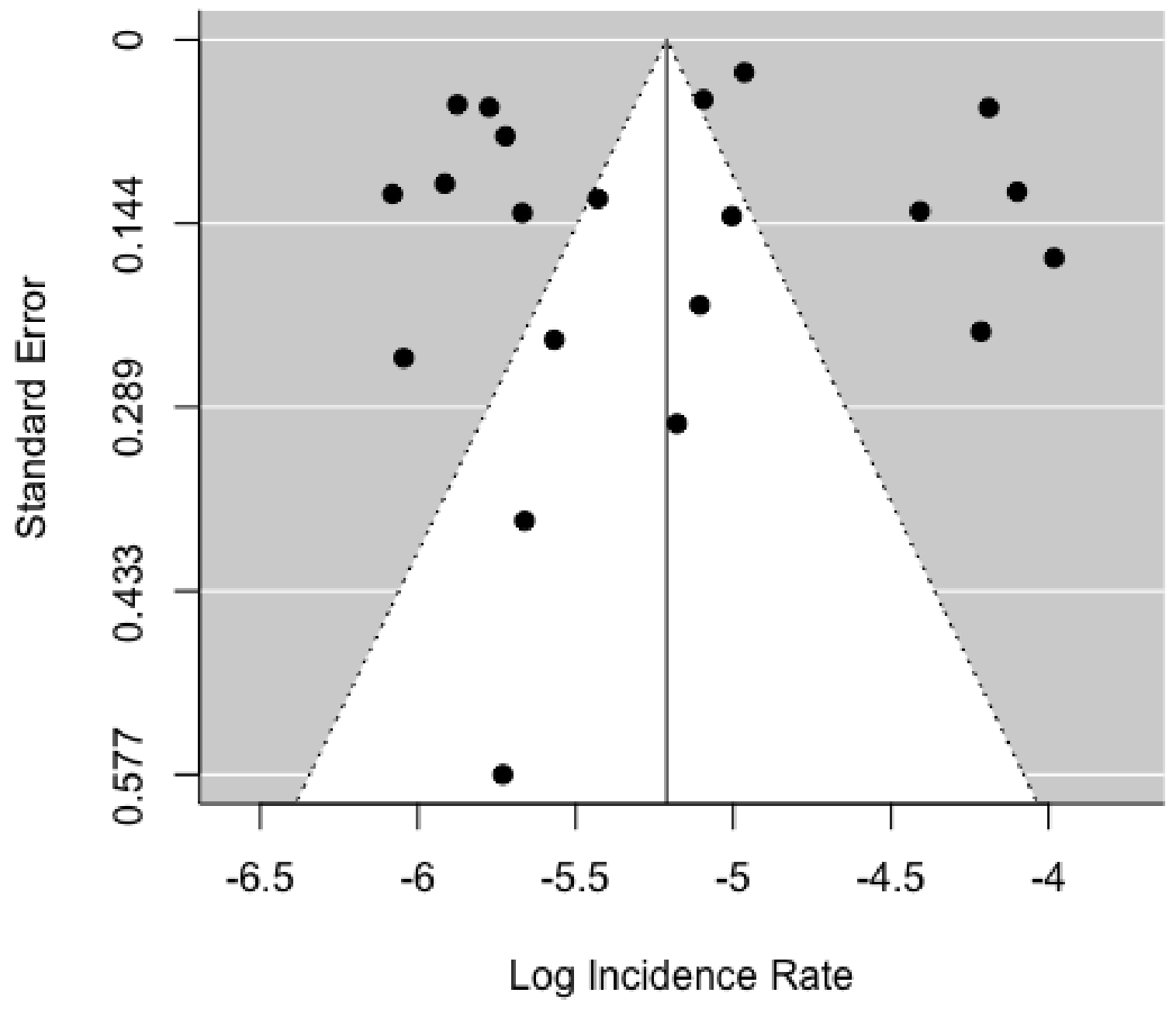

- Funnel plot for risk of publication bias in crude overdose-specific mortality rate appeared grossly symmetric.

- Rank Correlation Test for Funnel Plot Asymmetry

$\circ \quad$ Kendall's tau $=0.0476, \mathrm{p}=0.7884$

- Regression Test for Funnel Plot Asymmetry

o model: mixed-effects meta-regression model

o predictor: standard error

$\bigcirc$ test for funnel plot asymmetry: $z=-0.5015, p=0.6160$

- Trim \& Fill

$\circ \quad$ Estimated number of missing studies on the right side: $1(\mathrm{SE}=2.9218)$

$\circ \mathrm{Tau}^{2}=0.4691(\mathrm{SE}=0.1553), \mathrm{I}^{2}=98.58 \% ; \mathrm{H}^{2}=70.32 ; \mathrm{Q}(\mathrm{df}=21)=1139.8436$ 
Appendix 6. Leave-out-one meta-analysis for all-cause mortality reduction with opioid agonist therapy

Studies

Overall

- Brugal et al. 2005

- Buster et al. 2002

- Caplehorn et al. 1994

- Caplehorn et al. 1996

- Clausen et al. 2008

- Cornish et al. 2010

- Cornish et al. 2010b

- Cousins et al. 2011

- Cousins et al. 2016

- Cushman 1997

- Davoli et al. 2007

- Degenhardt et al. 2009

- Degenhardt et al. 2009b

- Esteban et al. 2003

- Evans et al. 2015

- Fugelstad et al. 1995

- Fugelstad et al. 1998

- Fugelstad et al. 2007

- Gearing et al. 1974

- Gr.nbladh et al. 1990

- Huang et al. 2011

- Huang et al. 2013

- Kimber et al. 2015

- Kimber et al. 2015b

- Nosyk et al. 2015

- Peles et al. 2010

- Reece 2010b

- Risser et al. 2001

- Russolillo et al. 2018

- Scherbaum et al. 2002

- Soyka et al. 2006

- Soyka et al. 2006b
Estimate (95\% C.I.)

$0.372(0.322,0.430)$

$0.369(0.316,0.430)$

$0.361(0.312,0.417)$

$0.373(0.321,0.432)$

$0.374(0.323,0.434)$

$0.371(0.319,0.431)$

$0.373(0.321,0.433)$

$0.368(0.318,0.426)$

$0.377(0.325,0.437)$

$0.374(0.322,0.435)$

$0.374(0.322,0.433)$

$0.378(0.327,0.437)$

$0.369(0.313,0.436)$

$0.361(0.312,0.417)$

$0.360(0.311,0.415)$

$0.372(0.319,0.434)$

$0.373(0.322,0.432)$

$0.370(0.320,0.429)$

$0.370(0.319,0.431)$

$0.377(0.325,0.437)$

$0.373(0.322,0.433)$

$0.380(0.329,0.439)$

$0.367(0.317,0.426)$

$0.364(0.314,0.422)$

$0.371(0.318,0.432)$

$0.388(0.340,0.444)$

$0.386(0.336,0.445)$

$0.371(0.320,0.430)$

$0.377(0.325,0.437)$

$0.371(0.316,0.434)$

$0.378(0.326,0.438)$

$0.370(0.319,0.428)$

$0.369(0.319,0.427)$

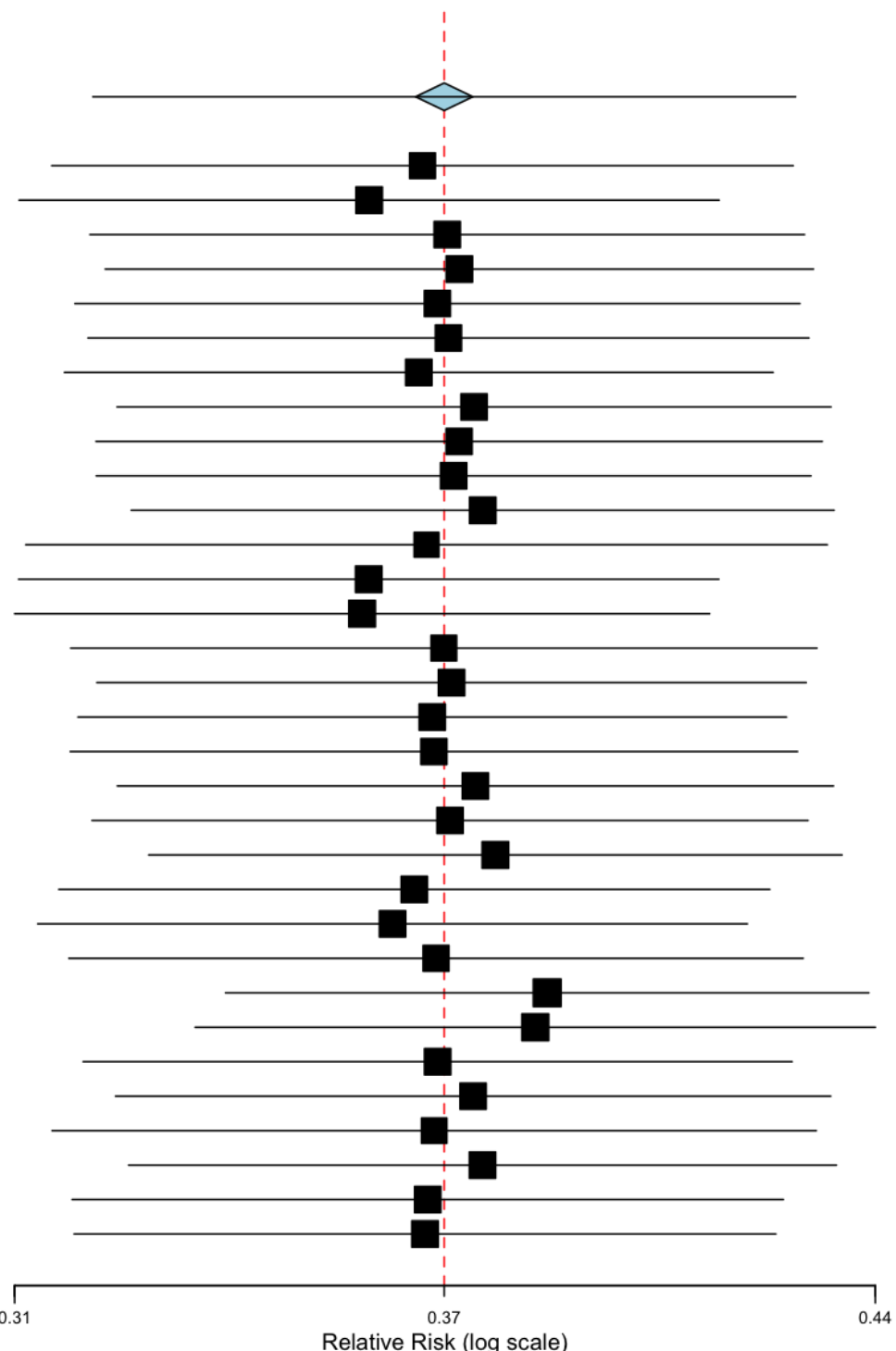

This article is protected by copyright. All rights reserved. 
Appendix 7. Leave-out-one meta-analysis for overdose-specific mortality reduction with opioid agonist therapy

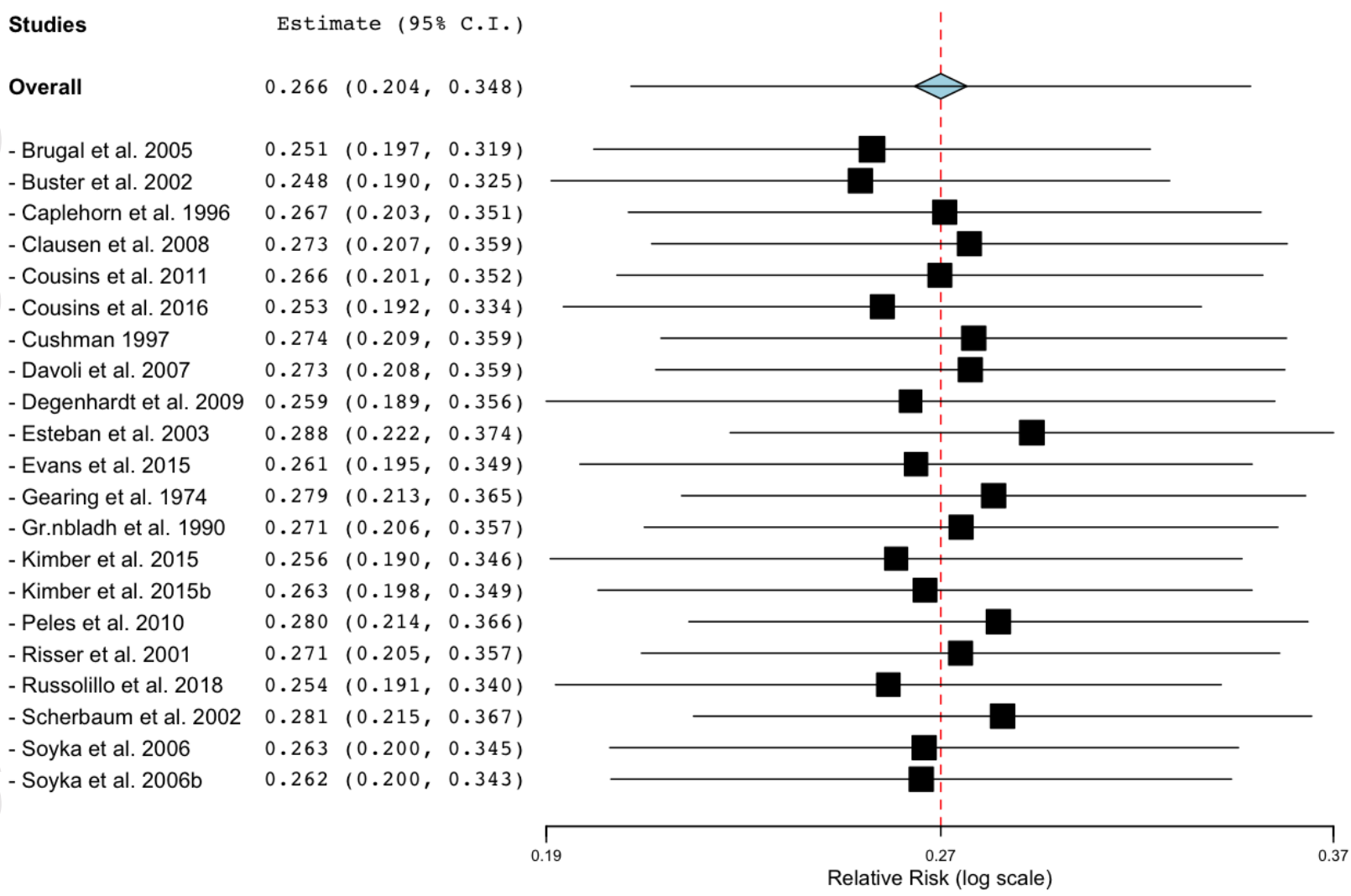

This article is protected by copyright. All rights reserved. 
Appendix 8. Absolute all-cause crude mortality rates within and outside of opioid agonist therapy treatment

\begin{tabular}{|r|c|c|c|c|c|c|}
\hline & Est. (per 1000 PY) & $95 \% \mathrm{CI}$ & $k$ & \multicolumn{1}{|c|}{$I^{2}$} & $Q$ & $p$ \\
\hline Oll-cause CMR & 13.5 & $10.1-17.9$ & 32 & 99.41 & 3520.0315 & $<.0001$ \\
\hline Treatment Class & & & & & & \\
\hline Methadone & 14.9 & $10.8-20.5$ & 27 & 99.49 & 3285.4341 & $<.0001$ \\
\hline In Treatment & 7.4 & $6.3-8.8$ & 5 & 59.38 & 7.9869 & 0.0921 \\
\hline Ouprenorphine & & & & & & \\
\hline Buprenorphine & 8.6 & $6.4-11.6$ & 32 & 98.20 & 976.9908 & $<.0001$ \\
\hline Out of Treatment & 9.1 & $6.5-12.8$ & 27 & 98.55 & 931.6551 & $<.0001$ \\
\hline Overall & 6.0 & $3.9-9.2$ & 5 & 68.30 & 14.7081 & 0.0053 \\
\hline Methadone & 22.6 & $16.3-31.3$ & 32 & 99.31 & 2685.1150 & $<.0001$ \\
\hline Buprenorphine & 26.8 & $19.1-37.6$ & 27 & 99.31 & 2358.0911 & $<.0001$ \\
\hline First Four Weeks in Treatment & 8.6 & $6.5-11.3$ & 5 & 79.90 & 13.9189 & $<.0001$ \\
\hline Overall & 8.8 & $5.2-14.9$ & 12 & 89.53 & 153.2216 & $<.0001$ \\
\hline Methadone & 10.1 & $5.5-18.3$ & 9 & 91.99 & 132.3523 & $<.0001$ \\
\hline Buprenorphine & 4.5 & $2.5-8.1$ & 3 & 0.00 & 1.4007 & 0.4964 \\
\hline First Four Weeks off Treatment & & & & & & \\
\hline Overall & 31.5 & $14.6-68.0$ & 12 & 98.26 & 686.0263 & $<.0001$ \\
\hline Methadone & 32.9 & $12.1-89.1$ & 9 & 98.85 & 622.5066 & $<.0001$ \\
\hline Buprenorphine & 26.3 & $9.1-75.9$ & 3 & 87.52 & 14.6525 & 0.0007 \\
\hline Ofter Four Weeks in Treatment & & & & & & \\
\hline Methadone & 5.0 & $3.4-7.4$ & 12 & 97.99 & 258.3877 & $<.0001$ \\
\hline Buprenorphine & 4.7 & $2.8-8.1$ & 9 & 98.78 & 241.8985 & $<.0001$ \\
\hline Offer Four Weeks off Treatment & & $3.3-6.6$ & 3 & 47.63 & 4.1226 & 0.1273 \\
\hline Overall & 11.8 & $7.3-19.2$ & 12 & 99.38 & 603.3532 & $<.0001$ \\
\hline Methadone & 13.5 & $7.3-24.9$ & 9 & 99.53 & 515.5760 & $<.0001$ \\
\hline
\end{tabular}

$C M R=$ crude mortality rate; $95 \% C I=95 \%$ confidence interval for estimate; $p=$ probability of finding the observed value (or greater) by chance alone ( $p<$ 0.05 statistically significant); $k=$ number of studies reporting selected estimate; $I^{2}=$ measure of statistical heterogeneity; $Q=$ Cochrane's chi-square test of heterogeneity; $p(Q)=$ corresponding $p$-value for the Cochrane's chi-square test of heterogeneity; $P Y=$ person years of follow-up; NA = not applicable

This article is protected by copyright. All rights reserved. 
Appendix 9. Relative differences in all-cause crude mortality within and outside of opioid agonist therapy treatment

\begin{tabular}{|c|c|c|c|c|c|c|c|}
\hline All-cause CMR in/out of treatment & Estimate & $95 \% \mathrm{CI}$ & $p$ & $k$ & $I^{2}$ & $Q$ & $p(Q)$ \\
\hline Mortality Rate Difference (MRD) & Per 1000 PY & & & & & & \\
\hline Overall & 18.2 & $10.7-25.6$ & $<.0001$ & 32 & 99.54 & 523.0815 & $<.0001$ \\
\hline Methadone & 21.8 & $13.3-30.3$ & $<.0001$ & 27 & 99.58 & 497.0774 & $<.0001$ \\
\hline Buprenorphine & 3.0 & $-0.1-6.1$ & 0.0581 & 5 & 65.01 & 12.4331 & $<.0001$ \\
\hline \multicolumn{8}{|l|}{ MRD: first four weeks } \\
\hline Overall & 63.4 & $-21.2-148.2$ & 0.1419 & 12 & 99.89 & 222.8883 & $<.0001$ \\
\hline Methadone & 79.5 & $-42.9-201.9$ & 0.2028 & 9 & 99.93 & 217.5059 & $<.0001$ \\
\hline Buprenorphine & 12.8 & $6.5-19.0$ & $<.0001$ & 3 & 2.03 & 2.8452 & 0.2411 \\
\hline \multicolumn{8}{|l|}{ MRD: after four weeks } \\
\hline Overall & 10.2 & $1.7-18.8$ & 0.0190 & 12 & 99.62 & 216.7259 & $<.0001$ \\
\hline Methadone & 13.4 & $2.0-24.7$ & 0.0211 & 9 & 99.73 & 206.1885 & $<.0001$ \\
\hline Buprenorphine & 3.2 & $-1.7-8.0$ & 0.1998 & 3 & 87.56 & 6.2859 & 0.0432 \\
\hline \multicolumn{8}{|l|}{ Mortality Rate Ratio (MRR) } \\
\hline Overall & 2.70 & $2.25-3.24$ & $<.0001$ & 32 & 90.00 & 183.5340 & $<.0001$ \\
\hline Methadone & 2.89 & $2.40-3.50$ & $<.0001$ & 27 & 90.35 & 167.4230 & $<.0001$ \\
\hline Buprenorphine & 1.62 & $0.99-2.65$ & 0.0571 & 5 & 61.97 & 12.8583 & 0.0120 \\
\hline \multicolumn{8}{|l|}{ MRR: first four weeks } \\
\hline Overall & 3.57 & $1.79-7.12$ & 0.0003 & 12 & 89.50 & 129.3119 & $<.0001$ \\
\hline Methadone & 3.29 & $1.37-7.89$ & 0.0078 & 9 & 93.21 & 126.1002 & $<.0001$ \\
\hline Buprenorphine & 4.25 & $2.17-8.33$ & $<.0001$ & 3 & 0.00 & 0.2763 & 0.8710 \\
\hline \multicolumn{8}{|l|}{ MRR: after four weeks } \\
\hline Overall & 2.37 & $1.95-2.87$ & $<.0001$ & 12 & 83.27 & 66.6493 & $<.0001$ \\
\hline Methadone & 2.50 & $1.98-3.17$ & $<.0001$ & 9 & 87.88 & 60.4455 & $<.0001$ \\
\hline Buprenorphine & 1.78 & $1.01-3.16$ & 0.0479 & 3 & 71.12 & 5.7859 & 0.0554 \\
\hline
\end{tabular}

$C M R=$ crude mortality rate; $95 \% C I=95 \%$ confidence interval for estimate; $p=$ probability of finding the observed value (or greater) by chance alone ( $p<$ 0.05 statistically significant); $k=$ number of studies reporting selected estimate; $I^{2}=$ measure of statistical heterogeneity; $Q=C o c h r a n e$ 's chi-square test of heterogeneity; $p(Q)=$ corresponding $p$-value for the Cochrane's chi-square test of heterogeneity; $P Y=$ person years of follow-up; NA = not applicable

This article is protected by copyright. All rights reserved. 
Appendix 10. Absolute overdose-specific crude mortality rates within and outside of opioid agonist therapy treatment

\begin{tabular}{|c|c|c|c|c|c|c|}
\hline Overdose CMR & Est. (per $1000 \mathrm{PY}$ ) & $95 \% \mathrm{CI}$ & $k$ & $I^{2}$ & $Q$ & $p$ \\
\hline Overall & 5.5 & $4.0-7.4$ & 21 & 98.55 & 1086.4248 & $<.0001$ \\
\hline \multicolumn{7}{|l|}{ Treatment Class } \\
\hline Methadone & 5.7 & $4.2-7.8$ & 19 & 98.66 & 1024.2360 & $<.0001$ \\
\hline Buprenorphine & 3.3 & $2.8-3.8$ & 2 & 0.00 & 0.0002 & 0.9891 \\
\hline \multicolumn{7}{|l|}{ In Treatment } \\
\hline Overall & 2.8 & $2.1-3.6$ & 21 & 93.08 & 313.6804 & $<.0001$ \\
\hline Methadone & 2.9 & $2.2-3.9$ & 19 & 93.18 & 272.6096 & $<.0001$ \\
\hline Buprenorphine & 2.2 & $0.7-6.8$ & 2 & 73.07 & 3.7140 & 0.0540 \\
\hline \multicolumn{7}{|l|}{ Out of Treatment } \\
\hline Overall & 11.5 & 7.7-11.71 & 21 & 98.86 & 872.5435 & $<.0001$ \\
\hline Methadone & 12.4 & $8.2-18.8$ & 19 & 98.88 & 795.1033 & $<.0001$ \\
\hline Buprenorphine & 4.6 & $3.9-5.4$ & 2 & 0.00 & 0.3821 & 0.5365 \\
\hline \multicolumn{7}{|l|}{ First Four Weeks in Treatment } \\
\hline Overall & 3.6 & $1.6-8.2$ & 5 & 83.70 & 16.97 & 0.0020 \\
\hline Methadone & 4.6 & $2.1-10.0$ & 4 & 81.37 & 11.43 & 0.0096 \\
\hline Buprenorphine & 1.0 & $0.2-3.8$ & 1 & NA & 0.00 & 1.00 \\
\hline \multicolumn{7}{|l|}{ First Four Weeks off Treatment } \\
\hline Overall & 8.3 & $3.0-23.2$ & 5 & 91.67 & 37.0783 & $<.0001$ \\
\hline Methadone & 7.6 & $2.0-29.3$ & 4 & 92.56 & 37.0582 & $<.0001$ \\
\hline Buprenorphine & 10.8 & $6.8-17.1$ & 1 & NA & 0.00 & 1.00 \\
\hline \multicolumn{7}{|l|}{ After Four Weeks in Treatment } \\
\hline Overall & 1.9 & $1.6-2.3$ & 5 & 55.23 & 8.9218 & 0.0631 \\
\hline Methadone & 2.0 & $1.6-2.5$ & 4 & 55.23 & 6.9723 & 0.0728 \\
\hline Buprenorphine & 1.5 & $1.0-2.1$ & 1 & NA & 0.00 & 1.00 \\
\hline \multicolumn{7}{|l|}{ After Four Weeks off Treatment } \\
\hline Overall & 4.2 & $3.0-5.8$ & 5 & 87.65 & 17.1815 & 0.0018 \\
\hline Methadone & 4.1 & $2.6-6.6$ & 4 & 86.56 & 16.7453 & 0.0008 \\
\hline Buprenorphine & 4.2 & $3.5-5.0$ & 1 & NA & 0.00 & 1.00 \\
\hline
\end{tabular}

$C M R=$ crude mortality rate; $95 \% C I=95 \%$ confidence interval for estimate; $p=$ probability of finding the observed value (or greater) by chance alone ( $p<$ 0.05 statistically significant); $k=$ number of studies reporting selected estimate; $I^{2}=$ measure of statistical heterogeneity; $Q=$ Cochrane's chi-square test of heterogeneity; $p(Q)=$ corresponding $p$-value for the Cochrane's chi-square test of heterogeneity; $P Y=$ person years of follow-up; NA = not applicable

This article is protected by copyright. All rights reserved. 
Appendix 11. Relative differences in overdose-specific crude mortality within and outside of opioid agonist therapy treatment

\begin{tabular}{|c|c|c|c|c|c|c|c|}
\hline Overdose CMR in vs. out of treatment & Estimate & $95 \% \mathrm{CI}$ & $p$ & $k$ & $I^{2}$ & $Q$ & $p(Q)$ \\
\hline Mortality Rate Difference (MRD) & Per $1000 \mathrm{PY}$ & & & & & & \\
\hline Overall & 9.9 & $5.4-14.4$ & $<.0001$ & 21 & 99.36 & 339.7977 & $<.0001$ \\
\hline Methadone & 11.1 & $6.3-15.9$ & $<.0001$ & 19 & 99.34 & 333.8455 & $<.0001$ \\
\hline Buprenorphine & 1.0 & $-5.0-7.0$ & 0.7338 & 2 & 63.88 & 2.7686 & 0.0961 \\
\hline \multicolumn{8}{|l|}{ MRD: first four weeks } \\
\hline Overall & 4.5 & $-2.8-11.9$ & 0.2238 & 5 & 88.19 & 26.1832 & $<.0001$ \\
\hline Methadone & 3.6 & $-6.1-13.3$ & 0.4706 & 4 & 90.84 & 15.8177 & 0.0012 \\
\hline Buprenorphine & 9.8 & $4.7-14.9$ & 0.0002 & 1 & NA & 0 & 1.00 \\
\hline \multicolumn{8}{|l|}{ MRD: after four weeks } \\
\hline Overall & 2.2 & $0.8-3.7$ & 0.0030 & 5 & 86.04 & 20.2233 & 0.0005 \\
\hline Methadone & 2.1 & $0.1-4.1$ & 0.0351 & 4 & 87.37 & 19.4751 & 0.0002 \\
\hline Buprenorphine & 2.8 & $1.9-3.7$ & $<.0001$ & 1 & NA & 0 & 1.00 \\
\hline \multicolumn{8}{|l|}{ Mortality Rate Ratio (MRR) } \\
\hline Overall & 3.88 & $2.74-5.51$ & $<.0001$ & 21 & 93.55 & 169.6250 & $<.0001$ \\
\hline Methadone & 4.06 & $2.80-5.88$ & $<.0001$ & 19 & 94.19 & 167.4642 & $<.0001$ \\
\hline Buprenorphine & 1.80 & $0.27-12.10$ & 0.5438 & 2 & 51.75 & 2.0724 & 0.1500 \\
\hline \multicolumn{8}{|l|}{ MRR: first four weeks } \\
\hline Overall & 2.42 & $0.67-8.74$ & 0.1765 & 5 & 84.98 & 22.1676 & 0.0002 \\
\hline Methadone & 1.72 & $0.43-6.82$ & 0.4408 & 4 & 85.42 & 17.0547 & 0.0007 \\
\hline Buprenorphine & 11.26 & $2.61-48.52$ & 0.0012 & 1 & NA & 0 & 1.00 \\
\hline \multicolumn{8}{|l|}{ MRR: after four weeks } \\
\hline Overall & 2.19 & $1.46-3.27$ & 0.0001 & 5 & 77.60 & 14.7889 & 0.0052 \\
\hline Methadone & 2.02 & $1.22-3.33$ & 0.0062 & 4 & 80.02 & 14.1115 & 0.0028 \\
\hline Buprenorphine & 2.89 & $1.93-4.33$ & $<.0001$ & 1 & NA & 0 & 1.00 \\
\hline
\end{tabular}

$C M R=$ crude mortality rate; $95 \% C I=95 \%$ confidence interval for estimate; $p=$ probability of finding the observed value (or greater) by chance alone ( $p<$ 0.05 statistically significant); $k=$ number of studies reporting selected estimate; $I^{2}=$ measure of statistical heterogeneity; $Q=$ Cochrane's chi-square test of heterogeneity; $p(Q)=$ corresponding $p$-value for the Cochrane's chi-square test of heterogeneity; $P Y=$ person years of follow-up; NA = not applicable

This article is protected by copyright. All rights reserved. 


\section{REFERENCES}

1. Degenhardt L, Charlson F, Mathers B et al. The global epidemiology and burden of opioid dependence: results from the global burden of disease 2010 study. Addiction 2014;109:1320-1333.

2. BAHJI A, BAJAJ N. Opioids on Trial: A Systematic Review of Interventions for the Treatment and Prevention of Opioid Overdose. Canadian Journal of Addiction 2018;9:26.

3. Nielsen S, Larance B, Degenhardt L, Gowing L, Kehler C, LintZeris N. Opioid agonist treatment for pharmaceutical opioid dependent people. Cochrane Database of Systematic Reviews Published Online First: 2016. doi:10.1002/14651858.CD011117.pub2

4. BAHJI A. An Epidemic of Incompetence: A Critical Review of Addictions Curriculum in Canadian Residency Programs. MedEdPublish 2019;8. doi:10.15694/mep.2019.000003.1

5. Health Quality Ontario. Opioid Prescribing for Chronic Pain. 2018.http://www.hqontario.ca/Evidence-to-Improve-Care/Quality-Standards/View-allQuality-Standards/Opioid-Prescribing-for-Chronic-Pain (accessed 30 Sep2018).

6. Kumar T, Rosenberg H. Take-home naloxone. CMAJ 2017;189:E1192-E1192.

7. Goldman-Hasbun J, DeBeck K, Buxton Ja, Nosova E, Wood E, Kerr T. Knowledge and possession of take-home naloxone kits among street-involved youth in a Canadian setting: a cohort study. Harm Reduct J 2017;14:79.

8. Fischer B, REHM J, TyNdAll M. Effective Canadian policy to reduce harms from prescription opioids: learning from past failures. CMAJ 2016;188:1240-1244.

9. RICH JD, MCKENZIE M, LARNEY S et al. Methadone continuation versus forced withdrawal on incarceration in a combined US prison and jail: a randomised, open-label trial. Lancet 2015;386:350-359.

10. CROWley D, VAN Hout M. Effectiveness of pharmacotherapies in increasing treatment retention and reducing opioid overdose death in individuals recently released from prison: A systematic review. Heroin Addiction and Related Clinical Problems 2017.

11. Gowing L, Farrell MF, Bornemann R, Sullivan LE, Ali R. Oral substitution treatment of injecting opioid users for prevention of HIV infection. Cochrane Database of Systematic Reviews Published Online First: 2011. doi:10.1002/14651858.CD004145.pub4

12. MAtTick RP, BReEN C, Kimber J, DAvoli M. Methadone maintenance therapy versus no opioid replacement therapy for opioid dependence. Cochrane Database Syst Rev 2009;:CD002209.

13. MatTick RP, BREen C, Kimber J, DAvoli M. Buprenorphine maintenance versus placebo or methadone maintenance for opioid dependence. Cochrane Database of Systematic Reviews Published Online First: 2014. doi:10.1002/14651858.CD002207.pub4

This article is protected by copyright. All rights reserved. 
14. Miller WR, Rollnick S. Motivational interviewing: Helping people change, 3rd edition. New York, NY, US: Guilford Press, 2013

15. Carroll K, Sinha R, Nich C, Babuscio T, Rounsaville B. Contingency management to enhance naltrexone treatment of opioid dependence: a randomized clinical trial of reinforcement magnitude. Experimental and clinical psychopharmacology 2002;10:54- 63 .

16. Gowing L, Ali R, White JM, Mbewe D. Buprenorphine for managing opioid withdrawal. Cochrane Database of Systematic Reviews Published Online First: 2017. doi:10.1002/14651858.CD002025.pub5

17. Minozzi S, Amato L, Bellisario C, Ferri M, Davoli M. Maintenance agonist treatments for opiate- dependent pregnant women. Cochrane Database of Systematic Reviews Published Online First: 2013. doi:10.1002/14651858.CD006318.pub3

18. Sordo L, Barrio G, Bravo MJ et al. Mortality risk during and after opioid substitution treatment: systematic review and meta-analysis of cohort studies. BMJ 2017;357:j1550.

19. Kimber J, Larney S, Hickman M, Randall D, Degenhardt L. Mortality risk of opioid substitution therapy with methadone versus buprenorphine: a retrospective cohort study. The Lancet Psychiatry 2015;2:901-908.

20. Degenhardt L, Bucello C, Mathers B et al. Mortality among regular or dependent users of heroin and other opioids: a systematic review and meta-analysis of cohort studies. Addiction 2011;106:32-51.

21. Faggiano F, Vigna- Taglianti F, Versino E, Lemma P. Methadone maintenance at different dosages for opioid dependence. Cochrane Database of Systematic Reviews Published Online First: 2003. doi:10.1002/14651858.CD002208

22. Liberati A, Altman DG, Tetzlaff J et al. The PRISMA Statement for Reporting Systematic Reviews and Meta-Analyses of Studies That Evaluate Health Care Interventions: Explanation and Elaboration. PLOS Medicine 2009;6:e1000100.

23. Stroup DF, Berlin JA, Morton SC et al. Meta-analysis of observational studies in epidemiology: a proposal for reporting. Meta-analysis Of Observational Studies in Epidemiology (MOOSE) group. JAMA 2000;283:2008-2012.

24. EgGer M, DAvey SMith G, SchneIDER M, Minder C. Bias in meta-analysis detected by a simple, graphical test. BMJ 1997;315:629-634.

25. Duval S, Tweedie R. Trim and fill: A simple funnel-plot-based method of testing and adjusting for publication bias in meta-analysis. Biometrics 2000;56:455-463.

26. BEGG CB, MAZUMDAR M. Operating characteristics of a rank correlation test for publication bias. Biometrics 1994;50:1088-1101.

27. Gasparrini A, ARMSTRONG B, Kenward MG. Multivariate meta-analysis for non-linear and other multi-parameter associations. Statistics in Medicine 2012;31:3821-3839.

This article is protected by copyright. All rights reserved. 
28. Berkey CS, Hoaglin DC, AntCZaK- Bouckoms A, Mosteller F, Colditz GA. Meta-analysis of multiple outcomes by regression with random effects. Statistics in Medicine 1998;17:2537-2550.

29. VIECHTBAUER W. Conducting Meta-Analyses in R with the metafor Package. Journal of Statistical Software 2010;36:1-48.

30. HigGINS JPT, THOMPSON SG. Quantifying heterogeneity in a meta-analysis. Stat Med 2002;21:1539-1558.

31. BAhJi A, HAWKen ER, SEPEHry AA, CABRERA CA, VAZQueZ G. ECT beyond unipolar major depression: systematic review and meta-analysis of electroconvulsive therapy in bipolar depression. Acta Psychiatr Scand 2019;139:214-226.

32. Furlan AD, MalmivaAra A, ChOu R et al. 2015 Updated Method Guideline for Systematic Reviews in the Cochrane Back and Neck Group. Spine 2015;40:1660-1673.

33. GEARING FR, SCHWEITZER MD. An epidemiologic evaluation of long-term methadone maintenance treatment for heroin addiction. Am J Epidemiol 1974;100:101-112.

34. Cushman P. Ten Years of Methadone Maintenance Treatment: Some Clinical Observations. The American Journal of Drug and Alcohol Abuse 1977;4:543-553.

35. GRÖNBLADH L, ÖHLUND LS, GUNNE LM. Mortality in heroin addiction: impact of methadone treatment. Acta Psychiatrica Scandinavica 1990;82:223-227.

36. CAPLEHORN JR. A comparison of abstinence-oriented and indefinite methadone maintenance treatment. Int J Addict 1994;29:1361-1375.

37. Caplehorn JRM, Dalton MYNS, Haldar F, Petrenas A-M, Nisbet JG. Methadone Maintenance and Addicts' Risk of Fatal Heroin Overdose. Substance Use \& Misuse 1996;31:177-196.

38. Fugelstad A, Rajs J, Bottiger M, Verdier MG. Mortality among HiV-infected intravenous drug addicts in Stockholm in relation to methadone treatment. Addiction 1995;90:711-716.

39. Fugelstad A, Agren G, Romelsjö A. Changes in mortality, arrests, and hospitalizations in nonvoluntarily treated heroin addicts in relation to methadone treatment. Subst Use Misuse 1998;33:2803-2817.

40. RisSER D, HönigSCHNABL S, STICHENWIRTH M et al. Mortality of opiate users in Vienna, Austria. Drug Alcohol Depend 2001;64:251-256.

41. Buster MCA, VAN BRUSSEl GHA, VAN DEN BRINK W. An increase in overdose mortality during the first 2 weeks after entering or re-entering methadone treatment in Amsterdam. Addiction 2002;97:993-1001.

42. Scherbaum N, Specka M, Hauptmann G, Gastpar M. [Does maintenance treatment reduce the mortality rate of opioid addicts?]. Fortschr Neurol Psychiatr 2002;70:455-461.

This article is protected by copyright. All rights reserved. 
43. ESTEBAN J. Survival study of opioid addicts in relation to its adherence to methadone maintenance treatment. Drug and Alcohol Dependence 2003;70:193-200.

44. Brugal MT., Domingo-Salvany A., Puig R., Barrio G., García de Olalla P., De la FUENTE L. Evaluating the impact of methadone maintenance programmes on mortality due to overdose and aids in a cohort of heroin users in Spain. Addiction (Abingdon, England) 2005;100:981-989.

45. Soyka M, Apelt SM, Lieb M, WitTCHEN H-U. One-year mortality rates of patients receiving methadone and buprenorphine maintenance therapy: a nationally representative cohort study in 2694 patients. J Clin Psychopharmacol 2006;26:657-660.

46. Davoli M, BARgagli AM, Perucci CA et al. Risk of fatal overdose during and after specialist drug treatment: the VEdeTTE study, a national multi-site prospective cohort study. Addiction 2007;102:1954-1959.

47. Fugelstad A, Stenbacka M, Leifman A, Nylander M, Thiblin I. Methadone maintenance treatment: the balance between life-saving treatment and fatal poisonings. Addiction 2007;102:406-412.

48. Clausen T, AnChersen K, WaAl H. Mortality prior to, during and after opioid maintenance treatment (OMT): A national prospective cross-registry study. Drug and Alcohol Dependence 2008;94:151-157.

49. Degenhardt L, Randall D, Hall W, Law M, Butler T, Burns L. Mortality among clients of a state-wide opioid pharmacotherapy program over 20 years: risk factors and lives saved. Drug Alcohol Depend 2009;105:9-15.

50. CoRnish R, MACleod J, StRang J, Vickerman P, Hickman M. Risk of death during and after opiate substitution treatment in primary care: prospective observational study in UK General Practice Research Database. BMJ 2010;341:c5475.

51. Peles E, Schreiber S, Adelson M. 15-Year survival and retention of patients in a general hospital-affiliated methadone maintenance treatment (MMT) center in Israel. Drug and Alcohol Dependence 2010;107:141-148.

52. Cousins G, Teljeur C, Motterlini N, McCowan C, Dimitrov BD, Fahey T. Risk of drug-related mortality during periods of transition in methadone maintenance treatment: A cohort study. Journal of Substance Abuse Treatment 2011;41:252-260.

53. HuAng Y-F, KuO H-S, LEW-Ting C-Y et al. Mortality among a cohort of drug users after their release from prison: an evaluation of the effectiveness of a harm reduction program in Taiwan: Mortality in an IDU cohort. Addiction 2011;106:1437-1445.

54. HUANG CL-C, LEE CW. Factors associated with mortality among heroin users after seeking treatment with methadone: A population-based cohort study in Taiwan. Journal of Substance Abuse Treatment 2013;44:295-300.

55. Evans E., Kelleghan A., Li L. et al. Gender differences in mortality among treated opioid dependent patients. Drug and alcohol dependence 2015;155:228-235.

This article is protected by copyright. All rights reserved. 
56. Nosyk B, Min JE, Evans E et al. The Effects of Opioid Substitution Treatment and Highly Active Antiretroviral Therapy on the Cause-Specific Risk of Mortality Among HIV-Positive People Who Inject Drugs. Clin Infect Dis 2015;61:1157-1165.

57. Cousins G, Boland F, COURTNey B, BARry J, LyOns S, FAHEY T. Risk of mortality on and off methadone substitution treatment in primary care: a national cohort study. Addiction 2016;111:73-82.

58. Russolillo A, MoniruZzaman A, Somers JM. Methadone maintenance treatment and mortality in people with criminal convictions: A population-based retrospective cohort study from Canada. PLos Med 2018;15:e1002625.

59. REECE AS. Favorable mortality profile of naltrexone implants for opiate addiction. $\mathrm{J}$ Addict Dis 2010;29:30-50.

60. StRANG J, MCCAMBRIDGE J, BEST D et al. Loss of tolerance and overdose mortality after inpatient opiate detoxification: follow up study. BMJ 2003;326:959-960.

61. MCCOWAN C, KIDD B, FAHEY T. Factors associated with mortality in Scottish patients receiving methadone in primary care: retrospective cohort study. BMJ 2009;338:b2225.

62. Auriacombe M, Frangues P, Tignol J. Deaths attributable to methadone vs buprenorphine in France. JAMA 2001;285:45.

63. Pirnay S, Borron SW, Giudicelli CP, Tourneau J, Baud FJ, Ricordel I. A critical review of the causes of death among post-mortem toxicological investigations: analysis of 34 buprenorphine-associated and 35 methadone-associated deaths. Addiction 2004;99:978-988.

64. KLEBER HD. Pharmacologic treatments for opioid dependence: detoxification and maintenance options. Dialogues Clin Neurosci 2007;9:455-470.

65. Thomas CP, Fullerton CA, KIM M et al. Medication-Assisted Treatment With Buprenorphine: Assessing the Evidence. PS 2014;65:158-170.

66. Bell JR, Butler B, Lawrance A, Batey R, SAlmelainen P. Comparing overdose mortality associated with methadone and buprenorphine treatment. Drug and Alcohol Dependence 2009;104:73-77.

67. Higgins JPT, ThOMPSON SG, SPIEGELHALTER DJ. A re-evaluation of random-effects meta-analysis. J R Stat Soc Ser A Stat Soc 2009;172:137-159.

68. LiN L, CHU H, Hodges JS. Alternative Measures of Between-Study Heterogeneity in Meta-Analysis: Reducing the Impact of Outlying Studies. Biometrics 2017;73:156-166.

69. SCHMIDT FL, OH I-S, HAYES TL. Fixed- versus random-effects models in meta-analysis: model properties and an empirical comparison of differences in results. Br J Math Stat Psychol 2009;62:97-128.

70. Bell A, FAIRBROTHER M, Jones K. Fixed and random effects models: making an informed choice. Qual Quant 2019;53:1051-1074.

This article is protected by copyright. All rights reserved. 
71. Pavlou M, Ambler G, Seaman S, Omar RZ. A note on obtaining correct marginal predictions from a random intercepts model for binary outcomes. BMC Medical Research Methodology 2015;15:59.

72. Cochrane Collaboration. Cochrane Handbook: General Methods for Cochrnae Reviews. Heterogeneity. 2014.https://handbook-5-

1.cochrane.org/chapter_9/9_5_heterogeneity.htm (accessed 17 Jul2019).

73. Brogly SB, Saia KA, Walley AY, Du HM, Sebastiani P. Prenatal Buprenorphine Versus Methadone Exposure and Neonatal Outcomes: Systematic Review and MetaAnalysis. Am J Epidemiol 2014;180:673-686.

74. MANHAPRA A, QUINONES L, ROSENHECK R. Characteristics of veterans receiving buprenorphine vs. methadone for opioid use disorder nationally in the Veterans Health Administration. Drug and Alcohol Dependence 2016;160:82-89.

75. MAthers BM, Degenhardt L, Ali H et al. HIV prevention, treatment, and care services for people who inject drugs: a systematic review of global, regional, and national coverage. The Lancet 2010;375:1014-1028.

76. Soyka M, Winter C, Kagerer S, Brunnauer M, Laux G, MöLler H-J. Effects of haloperidol and risperidone on psychomotor performance relevant to driving ability in schizophrenic patients compared to healthy controls. J Psychiatr Res 2005;39:101-108.

This article is protected by copyright. All rights reserved. 